FEDERAL RESERVE BANK OF SAN FRANCISCO

WORKING PAPER SERIES

\title{
Technology Diffusion and Postwar Growth
}

\author{
Diego Comin \\ Harvard University and NBER \\ Bart Hobijn \\ Federal Reserve Bank of San Francisco \\ and Free University Amsterdam \\ June 2010 \\ Working Paper 2010-16 \\ http://www.frbsf.org/publications/economics/papers/2010/wp10-16bk.pdf \\ The views in this paper are solely the responsibility of the authors and should not be \\ interpreted as reflecting the views of the Federal Reserve Bank of San Francisco or the \\ Board of Governors of the Federal Reserve System.
}




\title{
Technology Diffusion and Postwar Growth
}

\author{
Diego Comin
}

Harvard University and NBER
Bart Hobijn

\author{
Federal Reserve Bank of San Francisco \\ and Free University Amsterdam
}

Version 3, June $12010^{*}$

Prepared for NBER Macroeconomics Annual 2010.

\begin{abstract}
In the aftermath of World War II, the world's economies exhibited very different rates of economic recovery. We provide evidence that those countries that caught up the most with the U.S. in the postwar period are those that also saw an acceleration in the speed of adoption of new technologies. This acceleration is correlated with the incidence of U.S. economic aid and technical assistance in the same period. We interpret this as supportive of the interpretation that technology transfers from the U.S. to Western European countries and Japan were an important factor in driving growth in these recipient countries during the postwar decades.
\end{abstract}

keywords: wars, economic growth, technology adoption, cross-country studies.

JEL-code: E13, O14, O33, O41.

\footnotetext{
*We would like to thank Daron Acemoglu, Chang-Tai Hsieh, James Robinson, Alan Taylor, and other participants of the NBER Macroannual Conference for their many comments and suggestions. Furthermore, we are grateful to Colin Gardiner, Salifou Issoufou, and Hitesh Makhija for their excellent research assistance as well as Kan Kin for his assistance with the literature survey. We are indebted to the NSF (Grants \# SES-0517910 and SBE-738101) for financial assistance. The views expressed in this paper solely reflect those of the authors and not necessarily those of the National Bureau of Economic Research, the Federal Reserve Bank of San Francisco, or those of the Federal Reserve System as a whole.
} 
Wars, and especially the Second World War (WWII), are extremely disruptive episodes that lead to a major destruction of productive resources. Glick and Taylor (2010) estimate that the total number of deaths in WWII is approximately 2 percent of the 1940 world population, while the wounded made up another 3 percent. Wolff (1991) reports that the war led to a destruction or dismantling of about a quarter of the capital stock in Germany and Japan. The arguably largely exogenous nature ${ }^{1}$ of these disruptions has made wars, and particularly the recoveries that follow them, episodes that are often studied to understand the transitional dynamics that drive economic growth.

What is especially puzzling about postwar recoveries is that countries have recovered at very different speeds after wars. For example, it took Spain 15 years to reach the preCivil-War level of per capita GDP. Conversely, Italy reached its pre-WWII GDP level just 6 years after the end of the war. One might be tempted to think that these different speeds of recovery are simply due to the different extent of war damage across countries. However, this turns out to be an oversimplified view of the dynamics that have driven postwar growth.

A common thread that emerged from the many studies of the postwar performance of Germany, Japan, and their industrialized counterparts, ${ }^{2}$ is that the standard Neoclassical growth model implies a much higher postwar convergence rate than observed during postwar growth recovery of these countries, especially that of Japan.

Furthermore, after growing at a substantially higher rate than their steady state growth rates for several decades after WWII many countries did not converge to their prewar growth trajectory. Instead, they converged to a growth path substantially higher than the one they were on before the war.

In our view, these failures of the Neoclassical growth model to account for the postwar economic growth experiences suggest the importance of the path of technological progress.

\footnotetext{
${ }^{1}$ Some evidence, for example Hess and Orphanides (1995) and Miguel, Satyanath, and Sergenti (2004), suggests that the timing of wars might not be completely exogenous.

${ }^{2}$ Van Ark and Pilat (1993) provide a detailed analysis of the performance of the manufacturing sectors. Cette, Kocoglu, and Mairesse (2009) study labor productivity and TFP measures for Japan, France, the U.K., and U.S.. Hayashi (1986, 1989), Christiano (1989), and Chen, Imrohoğlu, and Imrohoğlu (2006), focus on Japan in particular.
} 
Eaton and Kortum (1997) emphasize the importance of endogenous technology adoption for matching the postwar productivity growth experiences of the manufacturing sectors in the world's five leading industrialized economies. Gilchrist and Williams (2004) argue that endogenous productivity growth due to the putty-clay nature of capital does a better job of matching the postwar growth experience of these economies than the standard putty-putty neoclassical growth model. Chen, Imrohoğlu, and Imrohoğlu (2006), claim that in the case of Japan neoclassical transitional dynamics do just fine when one feeds the observed path of total factor productivity (TFP) growth into the standard growth model. However, they do not aim to explain how this TFP-path came about.

Hence, just like cross-country differences in TFP levels account for the bulk of the enormous disparities in GDP per capita levels, ${ }^{3}$ cross-country differences in TFP dynamics drive a large part of the differences in postwar growth experiences. It is thus not only important, as Prescott (1997) advocates, to have a theory of differences in TFP levels but it is also important to understand the sources of differences in the dynamics of TFP.

In this paper we study the extent to which these differences in TFP dynamics across countries can be accounted for by observed differences in technology adoption patterns. In particular, we explore the idea that wars, in addition to destroying capital, impact the costs of adopting new technologies. This may occur for a variety of reasons. Our main focus here is on the reduction in adoption costs due to the postwar economic aid and technical assistance provided by the United States to Japan and Western Europe.

We argue that this reduction of adoption costs mainly reflects technology transfers from the U.S. to other countries and that such transfers disproportionately involved knowledge about state-of-the-art, modern, technologies. If this would be an important factor driving postwar productivity growth, then we would observe a disproportionate acceleration in the speed of adoption of new technologies in the countries that received economic aid and technical assistance from the U.S. during the postwar period. We then document that this is

\footnotetext{
${ }^{3}$ See Klenow and Rodríguez-Clare (1997) and Hall and Jones (1999).
} 
what we observe in the data.

We do so in three steps. First, we introduce a model of technology adoption and economic growth, similar to Comin and Hobijn (2010), that allows us to estimate the speed of adoption of technologies, and changes in this speed, for many countries and technologies. We use data on direct measures of technology adoption from the CHAT dataset, described in Comin and Hobijn (2009b). These data cover major technologies related to transportation, communication, as well as electricity, and have not been extensively used in the cross-country analysis of postwar growth dynamics. We complement these data with data on population, real GDP, and consumption from Maddison (2007) and Barro and Ursúa (2008). This allows us to consider a sample of 10 technologies and 39 countries with a varying degree of involvement in WWII.

We then show that U.S. economic aid and technology assistance are strongly associated with the adoption of new technologies during the postwar period. In particular, the average country that benefitted from the program reduced the lags with which it adopted the new technologies in our sample by 4 years compared to other countries. For old technologies, instead, we find that the assistance programs led to an increase in the adoption lags after WWII. The differential effect of the technology assistance programs on new vs. old technologies persists after including country fixed effects. This finding reinforces our prior that the mechanism by which technology assistance reduces adoption lags is through a reduction in the costs of adopting technologies rather than through an overall improvement in efficiency, since the increases in efficiency associated with the latter would have a more symmetric effect across technologies. Furthermore, the effect of technology assistance on adoption lags is robust to controlling for institutional measures such as polity (or its postwar change) as well as policies such as openness to trade.

The differential effect of U.S. assistance on the pace of adoption of new and old technologies as well as the robustness of the results to country fixed effects suggests that there were substantial forces beyond economy-wide effects, emphasized by for example Delong and 
Eichengreen (1991) and Eichengreen (2007), that drove the acceleration in technology adoption in the countries. In addition, we use the classification method of technologies applied in Comin and Hobijn (2009a) to show that this differential effect across technologies is not such that technologies subject to more lobbying saw a bigger decline in their adoption lags. Thus, we conclude that we find little evidence in support of Olson's (1982) hypothesis that WWII led to the decline distributional coalitions that had slowed down technology adoption in Japan and Western Europe before the onset of the war.

Finally, we find that the reduction in the lags with which countries adopted new technologies explains a significant part of postwar growth differentials between countries, even when one controls for differences in institutions and openness to trade. Though this correlation is by no means a proof of causation, we do interpret it as indicative of the importance of U.S. technology transfers for postwar growth differentials across countries.

The structure of the paper is as follows. In Section 1 we document the main facts about the damage incurred by countries during WWII and the differences in their subsequent growth experiences. We augment the evidence on real GDP per capita with evidence on the impact of the war on technology usage and the subsequent recovery in the technology-specific measures for different countries. We also discuss the U.S. economic and technical assistance to Japan and Western Europe. In Section 2 we introduce the model, solve for the optimal decisions of firms and households, and define equilibrium. In the next section we explain how the model maps into predictions for the path of observable measures of technology adoption and use this mapping to derive reduced form equations that allow us to estimate adoption lags. We discuss the resulting estimates of the changes in the adoption lags and their implications in Section 4. We conclude with Section 5. ${ }^{4}$

\footnotetext{
${ }^{4}$ The details of the derivations of the equations in the main text are available in an online Appendix that is part of the NBER Working Paper version of this article.
} 


\section{WWII damage and subsequent growth}

A wide range of studies have documented the very strong growth experienced by many industrialized countries during the three decades that followed WWII. ${ }^{5}$ In this section we give a brief review of economic growth in industrialized countries during these decades. Since our emphasis is on technology adoption, we augment the GDP-based analysis, which is very similar to that in other studies, with facts about the use of technologies. We first discuss the damage done during the war and then proceed by documenting postwar growth.

Figure 1 depicts the decline in real GDP per capita and technology usage per capita for three technologies. Since we focus on per capita measures we implicitly correct for war deaths. Glick and Taylor (2010) tabulate estimated casualties for many countries. Their estimates suggest that the total number of deaths in WWII is approximately 2 percent of the 1940 world population, while the wounded made up another 3 percent.

Panel (a) of Figure 1 shows pre- and postwar levels of log real GDP per capita for the countries in our sample. The horizontal axis is the 1938 log real GDP per capita level, in deviation from that in 1946 in the U.S., while the vertical axis show the minimum of the 1945 and 1946 levels of log real GDP per capita. ${ }^{6}$ The dashed line is the 45-degree line.

Points below the 45-degree line depict countries that saw a GDP decline during the war. The vertical distance between the point and the 45-degree line approximately equals the percentage decline in real GDP per capita during the war. Germany, Japan, Austria, The Netherlands, Greece, as well as Indonesia, the Phillipines, and Taiwan all saw real GDP per capita declines in excess of 40 percent during WWII. To put this in a historical perspective, the decline in U.S. real GDP per capita during the Great Depression was approximately 30 percent. The U.S. and Canada geared up their industrial complexes to produce military supplies during the war period and actually saw substantial increases in real GDP per capita

\footnotetext{
${ }^{5}$ Among the many studies that touch upon this topic are Abramovitz (1986), Baumol (1986), De Long (1988), Wolff (1991), Van Ark and Pilat (1993).

${ }^{6}$ We take the minimum of 1945 and 1946 because WWII ended at different times during 1945 in different countries. Hence, the 1945 data thus partially reflect economic activity during the war rather than right after it ended.
} 


\section{during WWII.}

These declines in real GDP in war-ravaged countries coincided with substantial declines in the usage of many technologies. In terms of aggregate capital stock measures, Wolff (1991) reports that WWII led to a destruction or dismantling of about a quarter of the capital stock in Germany and Japan. Panels (b) through (d) of Figure 1 are the equivalent of panel (a) but then for three technology usage measures rather than for real GDP. The particular three technologies depicted are cars, electricity, and steam- and motorships, respectively.

The qualitative patterns in terms of declines in technology usage are very similar to those in real GDP. Countries that saw active combat on their soil during the war also saw very substantial declines in their technology usage. In fact, the merchant fleets of many countries were almost completely destroyed. Similarly, declines in cars per capita were much higher than those in real GDP per capita. Declines in electricity production, however, were less pronounced than those in overall economic activity.

The substantial declines in GDP and technology usage in war-ravaged countries was followed by a remarkable post-WWII rebound. This can be seen from Figure 2. It shows the path of log real GDP and technology usage per capita for three technologies for four countries in our sample. The countries that we have chosen for illustrative purposes are the United States, Germany, Japan, and Argentina. We follow De Long (1988) and De Long and Eichengreen (1991) here and include Argentina as an example of a country that, in spite of being relatively rich at the onset of the war and almost unscathed by WWII, did not see the type of catch-up with the United States in the postwar period that many other industrialized economies saw.

In terms of the paths of real GDP per capita (panel (a)), four things stand out from this figure. First, after all the turbulence of the Great Depression and WWII the U.S. ended up on approximately the same growth path it was on before 1929. Secondly, Argentina starts to steadily fall behind the U.S. after WWII. Argentinian per capita GDP was 84 percent of that of the U.S. in 1938 and declined to 24 percent in the 1970's. The final two things to 
take away from panel (a) are the most important for the rest of the analysis in this paper.

The first is that it took Germany and Japan until between 1955 and 1960 to return back to their prewar growth paths. The second is that, contrary to the U.S., both Germany and Japan did not converge to this prewar path but instead busted through it and converged to a growth path that was substantially higher than that in the prewar period.

Just like for the declines during WWII, the postwar experiences in terms of technology usage exhibit very similar qualitative patterns as those of real GDP per capita. The U.S. saw a relatively smooth path of technology usage for all of these technologies. Contrary to the path of log real GDP, however, these technology usage paths are inherently non-linear. Argentina, while comparable in terms of technology usage at the beginning of the century, ends up trailing the other three countries by the end of it.

After the substantial declines in technology usage due to WWII we documented in Figure 1, Germany and Japan returned back to their prewar technology usage paths about as fast or even slightly faster than they returned to their aggregate growth path. Moreover, just like for real GDP per capita, they did not converge back to this path but instead moved up to higher levels of technology usage. Of course, because of the non-linear nature of the technology usage path a more formal quantitative analysis of this claim requires taking a stance on the shape of this path, which is the reason that we introduce a theoretical model in Section 2.

Germany and Japan are by no means the only two countries that, after the war, converged to a higher growth path than they were on before. Many Western European countries experienced this period of "supergrowth." As Dumke (1990) points out, the initial hypothesis was that most of the postwar experiences of these countries could be interpreted as driven by standard capital (re-) accumulation after the destruction during the war. This is often referred to as the "Reconstruction Hypothesis" and is inspired by the standard neoclassical growth model with exogenous technological progress.

As better historical cross-country real GDP data became available in the 1980's, empirical 
studies (Abramovitz, 1986, Baumol, 1986) emphasized that the Reconstruction Hypothesis might be able to explain the return of these countries to their postwar growth paths but it fails to explain the upward shifts in these paths. In order to understand these shifts, one has to understand the determinants of the productivity growth differentials that caused them. The observation that it is productivity growth differentials and not capital accumulation that accounts for most of the variation in postwar growth experiences across industrialized countries is known as the "Productivity Hypothesis."

We show, in the remainder of this paper, that the productivity growth that is at the heart of this hypothesis coincided with an acceleration in the rate at which the countries that caught up the most with the U.S. in the postwar decades adopted new technologies. The question is: What is the main driver of this joint acceleration in productivity growth and technology adoption? Was there a common factor that drove both of them, or did one lead to the other or vice versa?

Technology adoption decisions and other productivity enhancements are endogenous to many factors. For the purpose of our argument we distinguish two types of such factors. The first are those that lead to direct increases in the overall efficiency of the economy which might then be amplified by an acceleration in the adoption of technologies. These include improvements in the capacity and quality of institutions, ${ }^{7}$ The second type of factors have small direct effects on productivity growth. Instead they affect productivity indirectly through the reduction of adoption costs and the associated increase in the rate of technology adoption. These factors include adoption history, ${ }^{8}$ and the international transfer of knowhow about new technologies.

In principle, observed exogenous variation in these latter factors could be used for an instrumental variables analysis to quantify the causal effect of technology adoption on productivity and economic growth. Unfortunately, such a source of exogenous variation is not available and, thus, such an instrumental variables approach not feasible.

\footnotetext{
${ }^{7}$ As in, for example, Acemoglu, Johnson and Robinson (2001).

${ }^{8}$ See Comin, Easterly and Gong (2010).
} 
Our approach here, instead, is to identify a factor that had large effects on adoption costs through technology transfers but the variation in which across countries was probably not exogenous. As an alternative to an instrumental variables approach, we then exploit the different cross-technology implications of a reduction in adoption costs as opposed to those of other types of factors. The particular factor we focus on is postwar U.S. economic aid and technical assistance to Western Europe and Japan.

\subsection{Technical assistance and the Marshall Plan}

Following World War II, how did the U.S. go about providing technical assistance to Western Europe and Japan?

The Marshall Plan, otherwise known as the European Recovery Program, was unveiled to the world in the summer of 1947 by U.S. Secretary of State George Marshall. As Eichengreen and Uzan (1992) describe, initially the aim of the program was to provide direct economic relief to Western Europe in the form of capital transfers as well as financing for investment and import purposes. While this initial effort was effective at alleviating the oppressive economic conditions in both the European commodities and capital markets, Boel (2003) argues that it failed to address the mounting productivity gap that had formed between the U.S. and Europe during WWII.

According to Boel (2003), Western Europe was experiencing "worsening trade and payment deficit[s]" which stemmed from the considerable productivity gap and its inability to compete economically. Due to these conditions, the U.S. expanded and focused the Marshall Plan by instituting the Technical Assistance and Productivity Programme in 1949 (Bjarnar and Kipping, 1998). The main thrust of the Technical Assistance Program (TAP) was to increase productivity in Western Europe. The conventional wisdom surrounding the productivity gap was that Europe had technologically fallen behind the U.S. To address these concerns, the U.S. used the TAP as a conduit through which to disseminate state-of-the-art technologies, technical knowledge, and managerial sciences. 
The channels through which the technological transfer occurred inherently revolved around the lending of U.S. specialists to Europe and the allowance of their European counterparts to visit and observe processes in the U.S. Additionally, U.S. government agencies played an important role in transferring technological advances. The BLS, for example, contributed by providing statistical technical assistance which involved the exchange of specialists but also was focused on introducing a data and statistics-rich approach to productive efficiency in Western Europe (Wasser \& Dolfman, 2005).

Europe was not the sole beneficiary of these productivity and technology exchanges. Tiratsoo (2000) documents how the U.S. in 1955 initiated its technical assistance program to Japan. Like the TAP in Western Europe, the Japanese assistance plan focused on increasing technological and productive know-how.

Anecdotal evidence provided in several studies reveals the very significant impact these technical assistance programs had on the productivity of individual companies and industries as a whole.

For example, Tiratsoo (2000) recounts that after the Mitsubishi Company received technical assistance from the US in building a new assembly plant it was able to increase productive capacity by roughly $40 \%$. The International Directory of Company Histories (Saint James Press, 2001) describes how, in 1950, two leading executives of Toyota Motor Company,

“... seeking new ideas for Toyota's anticipated growth, ... toured Ford Motor Company's factories and observed the latest automobile production technology. One especially useful idea they brought home from their visit to Ford resulted in Toyota's suggestion system, in which every employee was encouraged to make suggestions for improvements of any kind."

Similar stories emerged about the U.S. technical assistance in Europe. Wasser and Dolfman (2005) cite one source as saying productivity within individual industries "commonly increased by 25 to 50 percent within a year with little or no investment" due to the TAP. 
Thus the TAP was not about stimulating productivity gains through capital spending as much as it was focused on the dissemination of technological and productive know-how about state-of-the-art technologies.

The extent of the knowledge transfers from the U.S. to Western Europe and Japan goes well-beyond the formal technical assistance program. U.S. efforts to boost productivity in its sphere of influence were part of a broader national security policy after 1953 and were in large part driven by the geopolitical realities of the Cold War.

What is important for the rest of our analysis is that the emphasis of these knowledge transfers was on modern, state-of-the-art, technologies. Because of this, if technical assistance related knowledge spillovers were an important driving force of a postwar acceleration in technology adoption in Western Europe and Japan, then we would this expect this to be especially the case for newer technologies.

\subsection{Other factors underlying postwar catch-up}

Most alternative explanations of the postwar "supergrowth" period have very different implications for the cross-technology variation in the changes in the speed of adoption from the old and new technology distinction emphasized above.

Explanations that emphasize country-specific rather than technology-specific explanations imply that, to a first order, the effect of postwar changes on technology adoption should be symmetric across technologies.

For example, Eichengreen (2007) emphasizes the reshuffling of the social contract between the government, employers, and workers, after WWII in Western Europe. He argues that this led to a type of "coordinated capitalism" with high savings and subdued wage growth. Such a process can definitely explain many facts about the postwar growth experiences of leading industrialized nations. However, it applies as much to old as to new technologies.

Similarly, explanations based on country-specific factors such as changes in institutions and openness to trade do not explain the differential pattern of reduction in adoption lags 
between new and old technologies. ${ }^{9}$

Besides country-specific factors, another factor often mentioned in relationship to the postwar productivity boost in Western Europe and Japan is Olson's (1982) theory of social rigidities. Olson argues that "the emasculation and abolishment of distributional coalitions..." during postwar occupation and as part of the Marshall Plan reduced the special interest groups that had lobbied to slow down technology adoption before WWII.

If Olson's (1982) mechanism is an important factor driving the acceleration of technology adoption after WWII then this acceleration would be particularly pronounced for technologies whose adoption impeded on the interest of these lobbying groups. To distinguish between technologies for which this could be important or not, we follow Comin and Hobijn (2009a) and classify technologies in our dataset into ones that are likely to be subject to lobbying and one that are not. Since this classification is different from the 'old' versus 'new' distinction we discussed before, this means that Olson's (1982) hypothesis has different cross-technology implications from the technical assistance factor we focus on.

To set the stage for the rest of our analysis, consider Figure 3. It depicts per capita GDP levels relative to the U.S. in 1950 and 1970 for the 39 countries in our sample. The further a country is above the 45-degree line the faster it caught up with the U.S. during the three decades following the war. Black dots represent countries that received substantial postwar U.S. economic aid and technical assistance. As can be seen from the picture, countries that received U.S. support seem to have caught up faster than their counterparts. What we show in the remainder of our analysis is that those countries that received U.S. support saw disproportionate declines in their technology gaps with the U.S. in terms of new technologies and that the change in this gap explains a significant part of the cross-country variation depicted in Figure 3.

In order to relate postwar growth to an acceleration in the speed of technology adoption,

\footnotetext{
${ }^{9}$ See Alvarez-Cuadrado and Pintea (2009) for a quantitive analysis of many of these factors in a theoretical growth model.
} 
we first need to quantify this speed. Because of the inherent non-linear nature of the technology usage measures depicted in panels (b)-(d) in Figure 2, quantifying this speed involves relating these non-linearities to an interpretable measure of the speed of technology adoption. For this purpose, we introduce a model of economic growth and technology adoption in the next section which relates cross country growth dynamics to our measures of technology usage and allows us to interpret their observed curvature in terms of the amount of time that elapses between the invention of a technology and when it gets adopted in a country. This delay is the adoption lag.

\section{Model with endogenous TFP and adoption lags}

We present a version of the model of technology adoption and growth introduced in Comin and Hobijn (2010). The model that we present serves two main purposes. First, it allows us to illustrate how the endogenously determined path of the adoption of technologies determines the equilibrium level of aggregate total factor productivity. Thus relating the pattern of technology adoption to the path of productivity that is so crucial for understanding the postwar experiences of many industrialized economies. Second, we use the model to show how the endogenous technology adoption patterns yield curvature in the time-path of measures of technology diffusion for which we have data. It is the curvature in these diffusion measures that we use to identify adoption lags in the data.

Contrary to Comin and Hobijn (2010), the analysis in this paper focuses on the transitional dynamics of the model. This is important, because of the emphasis on the postwar recovery in our analysis, which is inherently a realization of the transitional dynamics. ${ }^{10}$

Though our empirical analysis involves a cross-section of different technologies, we present our theoretical model here in a one-sector framework to simplify the exposition and to allow for the study of aggregate dynamics that are comparable with available cross-country data.

\footnotetext{
${ }^{10}$ Christiano (1989), Chen, Imrohoğlu, and Imrohoğlu (2006), for example, emphasize the importance of transitional dynamics for understanding the behavior of the Japanese saving rate since 1945. Gilchrist and Williams (2004) do so for both Germany and Japan.
} 


\subsection{Preferences and technology}

The unit measure of households in our model ${ }^{11}$ is assumed to have log preferences such that the optimal savings decision implies that the growth rate of consumption equals the difference between the real interest rate, $\widetilde{r}$, and the discount rate $\rho$. What is non-standard is the technology side of our model. It is the focus of the rest of this subsection.

\section{Capital vintages and adoption lags}

Our framework is one in which, as in Parente and Prescott (1994) and Eaton and Kortum (1997), the level of total factor productivity is determined by the distance between a country's productivity level and the world technology frontier. Throughout, we take the evolution of the world technology frontier as exogenous. ${ }^{12}$ Here we describe what, in particular, we mean by this distance. How this distance is the result of the technology adoption decisions of capital goods producers is explained later in this section.

The single good in this economy, which we use as the numeraire good such that it has a price of one, is produced using a Constant Elasticity of Substitution technology that is used to combine a continuum of intermediate goods each produced with their own specific capital vintage, $v$. At each instant, $t$, a new capital vintage is introduced, such that the set of available intermediate goods is given by $v \in \bar{V}=(-\infty, t]$.

We distinguish two groups of intermediates, indexed by $\tau$. The first, denoted by $\tau=o$, is the set of intermediates produced using old production methods, $v<\underline{v}$. The second, denoted by $\tau=n$, consists of intermediate goods produced using production methods that involve newer, more recently invented, $v \geq \underline{v}$, capital vintages. Hence, $\tau=o$ can be interpreted as the old technology and $\tau=n$ as the new one.

\footnotetext{
${ }^{11}$ Throughout, we ignore population growth and just adjust for it in the calibration of our parameters.

${ }^{12}$ Eaton and Kortum (1997) find, in a different theoretical framework, that endogenizing the path of the frontier does not improve the ability of their model to explain the postwar manufacturing productivity paths of Germany, Japan, France, the U.K., and the U.S..
} 
Aggregate output, $Y,{ }^{13}$ is produced using

$$
Y=\left(Y_{o}^{\frac{1}{\mu}}+Y_{n}^{\frac{1}{\mu}}\right)^{\mu}, \text { where } \mu>1
$$

and

$$
Y_{\tau}=\left(\int_{V_{\tau}} Y_{v}^{\frac{1}{\mu}} d v\right)^{\mu} \text { for } \tau=o, n .
$$

The set of vintages in use is thus given by $V=V_{o} \cup V_{n}$. However, not all available intermediates are necessarily used for the production of output, such that $V \subseteq \bar{V}$.

The use of a more expansive set of intermediates affects productivity in two ways. First of all, as already can be seen from (1) and (2), the use of more intermediates leads to a gain from variety. We call this type of productivity gain the variety effect.

The second effect is because technological progress is embodied in new capital vintages. Similar to Solow (1960), newer capital vintages are more productive than their older counterparts. This difference in productivity levels is reflected in the technologies with which the intermediate goods are produced. Each intermediate, $v$, is produced by combining labor, $L_{v}$, and capital, $K_{v}$, using a Cobb-Douglas production function of the form:

$$
Y_{v}=Z_{v} L_{v}^{1-\alpha} K_{v}^{\alpha}
$$

where $Z_{v}$ is the level of productivity embodied in the units of the capital vintage $v . Z_{v}$ is constant over time and is increasing in $v$. Let $\gamma$ be the growth rate of embodied technological change, then

$$
Z_{v}=Z_{0} e^{\gamma v} \text {, where } \gamma>0 .
$$

Hence, the world technology frontier consists of the productivity levels of the set of all available vintages $\bar{V}$. Moreover, if the set of technologies used, $V$, expands to include newer vintages, then this increases the overall productivity level. We refer to this as the embodiment

\footnotetext{
${ }^{13}$ Here, and in the rest of this article, to save on notation we drop the time subscript, $t$, whenever its presence is self-evident.
} 
effect of technology adoption.

If the most recent vintages are not used, then the embodied productivity level of the vintages in use falls short of that of the frontier. How much it falls short depends on the gap between the set of available and the set of used vintages.

Just like in Comin and Hobijn (2010) we consider the case in which the set of vintages in use is of the form $V=(-\infty, t-D]$. Here $D \geq 0$ is the time that elapsed since the invention of the newest capital vintage that is being used in production. It is the adoption lag.

\section{Capital goods production}

Each capital vintage, $v$, is produced by a single monopolistic competitor. Capital goods production is fully reversible and the unit production cost of a physical unit of capital is assumed to be constant across vintages and normalized to one unit of the final good. ${ }^{14}$ Capital goods depreciate at the rate $\delta$. Because the suppliers of these capital vintages have monopoly power, they can choose the rental rate $R_{v}$ at which they rent the capital stock out. The monopoly profits that these suppliers make are then used to pay off the initial adoption costs that they incurred to become the sole supplier of the particular capital vintage.

\section{Technology adoption}

In order to supply a particular capital vintage a firm has to incur a one-time adoption cost. These costs go up in the distance between the vintage adopted and the best vintage in place. In particular, let $\bar{v}_{t}=t-D_{t}$ denote the best vintage adopted at instant $t$, then the adoption of $v=\bar{v}_{t}+d t$ at instant $t+d t$ costs

$$
\Gamma_{v, t+d t}=e^{b \chi} \bar{\Psi}\left(\frac{\gamma}{\mu-1}\right)\left\{\frac{1}{\gamma} \frac{\frac{Z_{\bar{v}_{t}+d t}-Z_{\bar{v}_{t}}}{d t}}{Z_{\bar{v}_{t}}}\right\}\left(\frac{Z_{\bar{v}_{t}}}{Z_{t}}\right)^{\chi} Y_{t},
$$

\footnotetext{
${ }^{14}$ Comin and Hobijn (2010) are more specific about the distinction between investment-specific and embodied technological change. For the empirical methodology applied here, the distinction does not matter, however. Hence, we ignore it in the rest of our exposition.
} 
where $b>0$ and $\chi>0$.

Hence, the adoption costs increase in the rate at which the set of adopted vintages expands. However, they are lower, the further away one is from the world technology frontier, as reflected by the productivity of the most recent vintage invented, $Z_{t}$. The parameter $\chi$ can be interpreted as the absorption rate. Discrete jumps in the set of adopted vintages, and thus in the adoption lag, are infinitely expensive and do not occur. Instead, the adoption lags evolve smoothly over time.

The other parameter that determines the adoption costs is $b$, which is similar in interpretation to the barriers to adoption in Parente and Prescott (1994). ${ }^{15}$

The last term of the adjustment costs reflect that they are increasing in the size of the market. This is, on a theoretical level, important to assure the existence of a balanced growth path on which adoption lags are constant. Moreover, it is consistent with evidence that technology adoption involves a substantial use of resources beyond the installation of equipment. ${ }^{16}$ The costs of these resources are generally increasing in the size of the market, i.e. the marginal product of their use elsewhere in the economy.

\subsection{Factor demands, aggregation, and productivity}

\section{Factor demands}

The nested CES structure of the production function and the assumption that all factor inputs can adjust flexibly yields familiar expressions for the relative demands for intermediates and for prices. That is, the demand for the intermediate produced using vintage $v$ equals

$$
Y_{v}=Y\left(P_{v}\right)^{-\frac{\mu}{\mu-1}}
$$

\footnotetext{
${ }^{15} \bar{\Psi}$ is the steady-state stock market capitalization to GDP ratio, which is derived in the appendix. We include it and the other constant term to normalize the adoption costs to simplify the equilibrium expressions of the model.

${ }^{16}$ See Brynjolfsson and Hitt (2000) for an analysis of the costs of adoption of information technologies.
} 
where perfect competition in the production of intermediates yields that $P_{v}$ equals the unit production cost

$$
P_{v}=\frac{1}{Z_{v}}\left(\frac{W}{1-\alpha}\right)^{1-\alpha}\left(\frac{R_{v}}{\alpha}\right)^{\alpha}
$$

Here, $W$ is the real wage rate paid for the labor input $L_{v}$.

As in Comin and Hobijn (2010), the monopolistic competitor that supplies capital goods of vintage $v$ realizes that it faces a downward-sloping demand curve for its capital goods. This demand curve is downward sloping because an increase in the rental cost, $R_{v}$, raises the prices of the intermediates produced using capital vintage $v$. Such a price increase reduces demand for the intermediate good and thus for the capital goods used in their production. Taking this into account, the profit-maximizing rental rate, $R_{v}$, that the supplier of capital good $v$ chooses is equal to a gross-markup times the user-cost of capital. This rental rate is the same across capital vintages and equals

$$
R_{v}=\frac{\epsilon}{\epsilon-1}(\widetilde{r}+\delta)=R, \text { where } \epsilon \equiv 1+\frac{\alpha}{\mu-1} .
$$

This, combined with (7), implies that relative prices across intermediate inputs fully reflect relative embodied productivity levels for the capital vintages used to produce the intermediates.

\section{Aggregation}

The result is that we obtain very tractable aggregate production function representations. Because, for our empirical analysis, we use data at the technology level, i.e. $\tau \in\{o, n\}$, we build the aggregation results up from that level. That is, we can write the level of intermediate output associated with technology $\tau$ as

$$
Y_{\tau}=A_{\tau} K_{\tau}^{\alpha} L_{\tau}^{1-\alpha}, \text { where } K_{\tau} \equiv \int_{v \in V_{\tau}} K_{v} d v, L_{\tau} \equiv \int_{v \in V_{\tau}} L_{v} d v
$$


where the technology specific TFP level is given by

$$
A_{\tau}=\left(\int_{V_{\tau}} Z_{v}^{\frac{1}{\mu-1}} d v\right)^{\mu-1}
$$

For results used for our empirical application, it is useful to realize that this aggregation result implies that the unit production cost, and thus the price, of $Y_{\tau}$, equals

$$
P_{\tau}=\frac{1}{A_{\tau}}\left(\frac{W}{1-\alpha}\right)^{1-\alpha}\left(\frac{R_{\tau}}{\alpha}\right)^{\alpha}
$$

while the demand for output of technology $\tau$ is given by the iso-elastic demand function

$$
Y_{\tau}=Y\left(P_{\tau}\right)^{-\frac{\mu}{\mu-1}}
$$

and the rental cost share of capital is equal to $\alpha$, such that

$$
R_{\tau} K_{\tau}=\alpha P_{\tau} Y_{\tau}
$$

In a similar way, the technology-specific production functions yield an aggregate production function representation, which reads

$$
Y=A K^{\alpha} L^{1-\alpha} \text {, where } K \equiv K_{o}+K_{n}, L \equiv L_{o}+L_{n},
$$

and the aggregate level of total factor productivity

$$
A=\left(Z_{o}^{\frac{1}{\mu-1}}+Z_{n}^{\frac{1}{\mu-1}}\right)^{\mu-1}=\left(\int_{-\infty}^{t-D t} Z_{v}^{\frac{1}{\mu-1}} d v\right)^{\mu-1}
$$




\section{Productivity and adoption lags}

These aggregation results allow us to relate the technology-specific and aggregate productivity levels, $A_{\tau}$ and $A$, to the set of vintages adopted, i.e. to $V$, and thus to the adoption lags, $D$.

Solving for the technology-specific TFP level for the new technology yields

$$
A_{n}=\left(\frac{\mu-1}{\gamma}\right)^{\mu-1} Z_{\underline{v}} \underbrace{e^{\gamma(t-D-\underline{v})}}_{\text {embodiment effect }} \underbrace{\left[1-e^{-\frac{\gamma}{\mu-1}(t-D-\underline{v})}\right]^{\mu-1}}_{\text {variety effect }} .
$$

Here $(t-D-\underline{v})$ is the measure of vintages of the new technology that is in use, i.e. of $V_{n}=(\underline{v}, t-D]$. This measure shows up in two ways. First, through the embodiment effect, which reflects that the average embodied productivity level is increasing in the number of vintages of the new technology in use. This is what drives long-run growth in the adoption of the new technology and in the economy as a whole.

Second, the measure of vintages adopted also shows up because there are gains from variety in the CES production function. Since, in the long-run the growth rate of the number of varieties goes to zero, the variety effect is important during the early stages of adoption of the new technology and tapers off as the use of the technology becomes more widespread. It is this time-varying effect of the variety effect that drives curvature in the measured adoption of new technologies that we exploit in our empirical analysis.

The aggregate TFP level can be derived in a similar fashion. However, because aggregate TFP is driven by the whole set of vintages in use, i.e. $V=(-\infty, t-D]$, which does not have an expanding measure of vintages adopted, the aggregate TFP level is not subject to the variety effect. As a result, it can be written as

$$
A_{t}=A_{0} e^{\gamma(t-D)}, \text { where } A_{0}=Z_{0}\left(\frac{\mu-1}{\gamma}\right)^{\mu-1}
$$

Hence, aggregate TFP in this model is endogenously determined by the adoption lags induced 
by the barriers to entry. The adoption lag, $D$, can be interpreted as the distance from the world technology frontier measured in years.

\subsection{Optimal adoption}

So far, we have derived how the adoption lag affects the equilibrium level of productivity. We have not, however, solved for the optimal technology adoption decision that determines the lag. This is what we do here.

We denote the market value of a firm that supplies capital goods $v$ at instant $t$, after entry into the market, as $M_{v, t}$. Any vintage gets adopted whenever, at time $t$, this market value exceeds the adoption cost, $\Gamma_{v, t}$, a firm needs to incur to enter the market. That is, for all vintages $v$ that are being adopted at time $t$, it must be the case that

$$
\Gamma_{v, t} \leq M_{v, t}
$$

If there is a positive adoption lag, then this holds with equality for the best vintage that is being adopted.

As we derive in Appendix A, the market value of the firm that supplies capital vintage $v$ equals

$$
M_{v, t}=\int_{t}^{\infty} e^{-\int_{t}^{s} \widetilde{r}_{s^{\prime}} d s^{\prime}} \pi_{v s} d s=\left(\frac{Z_{v}}{A_{t}}\right)^{\frac{1}{\mu-1}} \Psi_{t} Y_{t}
$$

Here $\Psi_{t}$ is the total market value of all capital goods suppliers relative to GDP, which, if they are all publicly traded, can be interpreted as the stock market to GDP ratio.

Combining (5), (18), and (19), yields that the adoption lag satifies the differential equation

$$
\dot{D}_{t}=1-\left[\frac{\Psi_{t}}{\bar{\Psi}}\right] e^{\chi(\gamma D-b)} .
$$

The intuition behind this equation is as follows. The higher the current adoption lag, the cheaper the adoption of technologies and the more quickly the adoption lag declines. The 
higher the stock market to GDP ratio, $\Psi_{t}$, the higher the ratio of future benefits from adoption relative to the current costs and the faster the adoption lag declines. Finally, the higher the barriers to entry, $b$, the more expensive is technology adoption and the adoption lag will decline less quickly. In fact, in steady state, where $\dot{D}=0$, the adoption lag equals $b / \gamma$. In steady state, $b$ is the percentage productivity loss due to the barriers to entry.

\subsection{Equilibrium}

Equilibrium is defined in a similar way as in Comin and Hobijn (2010). The details of this definition are relegated to the technical appendix. Two non-standard features of the equilibrium are worth pointing out here.

First, for the aggregate equilibrium, it is important to know the amount of resources devoted to the adoption costs. The aggregate adoption costs in this economy turn out to equal

$$
\Gamma=\left(\frac{\gamma}{\mu-1}\right) \Psi Y
$$

Second, the aggregate resource constraint includes the aggregate adoption costs, such that

$$
Y=C+I+\Gamma .
$$

For our empirical analysis in Section 3 and beyond, we assume that adoption costs are measured as final demand. In particular, we assume that adjustment costs are measured as gross investment expenditures. This allows us to interpret $Y$ as measured GDP, $C$ as measured consumption, and $I+\Gamma$ as measured investment. ${ }^{17}$

The long-run growth rate of the economy only depends on the, exogenously given, growth rate of the world technology frontier. In particular, on the balanced growth path, this economy grows at rate $\gamma /(1-\alpha)$.

\footnotetext{
${ }^{17}$ Alternatively, one could define a GDP measure as $\widetilde{Y}=Y-\Gamma=\left[1-\left(\frac{\gamma}{\mu-1}\right) \Psi\right] Y=C+I$.
} 


\section{Identification and estimation of adoption lags}

So far, our focus has been on the aggregate dynamics of our model. When we described the model, we specifically defined an old and a new technology. Moreover, we derived the equilibrium path of output and capital for the new technology as a function of the adoption lags. We did so to be able to map the equilibrium variables in our model into observed measures of technology usage, taken from Comin and Hobijn (2009b). In this section we describe this mapping and how it allows us to obtain estimates of technology adoption lags.

\subsection{Technology measures}

The data we use from Comin and Hobijn (2009b) contain two types of measures of technology usage for a broad range of countries and a very long timespan. First, the equivalent of $Y_{n}$, is output produced with different technologies. Examples are mWHr of electricity generated, the number of telegrams sent, and the number of ton-kilometers of freight transported by rail. The second type of measure, equivalent to $K_{n}$, consists of the number of the units of capital goods used to produce a particular intermediate Like trucks that are used to provide road-freight transportation services, telephone. Examples of such measures were depicted in Figure 2. Table 1 contains a list of the 10 technologies we use for our analysis. The choice of these technologies is mainly determined by the data requirements of the method applied. That is, we choose technologies for which we have a substantial number of observations for many years and countries both before and after WWII. The table also includes the classification of the technologies into 'old' and 'new'. Technologies are classified as 'new' if they were invented after 1850 .

Our model has direct implications for the paths of these variables. This can be seen by

combining (11), (12), and (13) and taking logarithms. Denoting logs of variables by small 
letters, e.g. $y_{\tau}=\ln Y_{\tau}$, this yields that

$$
y_{\tau}=y+\frac{\mu}{\mu-1}\left[a_{\tau}-(1-\alpha)(y-l)-\alpha r_{\tau}-\alpha \ln \alpha\right]
$$

and

$$
k_{\tau}=y+\ln \alpha+\frac{1}{\mu-1}\left[a_{\tau}-(1-\alpha)(y-l)-\alpha r_{\tau}-\alpha \ln \alpha\right]-r_{\tau}
$$

The main driving force behind the curvature in the technology usage measures is the productivity term, $a_{\tau}$. To understand how the adoption lags affect this curvature, consider Figure 4. It plots the path of $a_{\tau}$ for five different cases. The first is the case vintages get adopted the instant they are invented, i.e. the world technology frontier. The curvature in the world technology frontier is driven by the variety effect. That is, in the early stages of the adoption of a technology the increase in the number of vintages causes growth to exceed the long run level of embodied technological change that sets in as the variety effect dissipates. The next two curves are those for constant adoption lags $D^{*}>D>0$. These curves are horizontal shifts in the world technology frontier, where the size of the shift determines the technology adoption lag. Two of the paths are based on simulations ${ }^{18}$ in which there is an acceleration in technology adoption in the sense that at first adoption lags are constant at $D^{*}$. However, at a certain point the adoption barriers are lowered and there is a transition toward shorter adoption lags of length $D$. What distinguishes these two paths is that for one the technology is relatively new while for the other it is older.

As can be seen from this figure, if the adoption lags are constant then they are identified by the relative curvature of the path of $a_{\tau}$ at a particular point in time. This is the identification strategy used in Comin and Hobijn (2010). However, our interest here is also in seeing whether we can identify changes in adoption lags over time for the same technology. The identification is a lot more complicated in that case. The initial adoption lag is determined

\footnotetext{
${ }^{18}$ These paths are simulated using parameter values that are chosen to match U.S. balanced growth properties and the postwar catch-up in real GDP relative to the U.S. by Japan. The basic shape of the paths plotted is not very sensitive to the parameter choice.
} 
by the curvature in the early part of the sample and the change in the adoption lag is implied by the change in the intercept between the extrapolated initial path and the actual observed path for $a_{\tau}$. The change in curvature in the middle part of the sample is due to the adjustment process. This change is what limits our analysis to technologies for which we have relatively long time-series evidence both before and after WWII.

\subsection{Reduced form equation}

To get from equations (23) and (24) to the reduced form equations we actually estimate, we take the steps described in this subsection. ${ }^{19}$

It turns out that, to first order, the productivity growth rate $\gamma$ does not matter for the variety effect and thus for the curvature in $a_{\tau}$. Therefore, as in Comin and Hobijn (2010), we $\log$-linearize $a_{\tau}$ around $\gamma=0$. Both $y_{\tau}$ and $k_{\tau}$ depend on the rental rate $r_{\tau}$. We use the optimal saving decision in the model to log-linearize the rental rate, which yields that $r_{\tau}$ is approximately proportional to the growth rate of consumption, $\Delta c .^{20}$

The final steps have to do with that, using data for several technologies, we need to drop the one-sector assumption we used to derive the model and need to generalize our functional forms to accommodate the multi-technology nature of our data.

Just like in Comin and Hobijn (2010), to allow for multiple sectors, we use a nested CES aggregator, where $\frac{\theta}{\theta-1}$ reflects the between-sector elasticity of demand and $\frac{\mu}{\mu-1}$ is the within-sector elasticity of demand. In addition, the embodied technological change, $\gamma_{\tau}$, and the invention date, $\underline{v}_{\tau}$, vary across technologies.

Finally, in Section 1 we documented very different rates of capital destruction during WWII across the different technologies in our dataset. Since the model we considered has flexible capital mobility, it would imply an immediate replenishment of these capital losses and equate them across technologies. Hence, our model is not consistent with this varying

\footnotetext{
${ }^{19}$ We limit ourselves to a short description and present the details behind these steps in the Appendix.

${ }^{20}$ Throughout, we have derived our results for $\log$ preferences, i.e. an intertemporal elasticity of substitution equal to 1 . This log-linear approximation actually holds for CRRA preferences with any intertemporal elasticity of substitution.
} 
impact. To match this feature of the data, we add a capital adjustment cost term to the equation. ${ }^{21}$ The adjustment cost variable is denoted by $X_{\tau}$ below. It equals the investment to capital ratio for $k_{\tau}$ and output growth rate for $y_{\tau} \cdot{ }^{22}$

We make the following assumption about the adoption lag: before the war it is equal to $D^{*}$ and starting in 1945 it potentially converges to $D \neq D^{*}$. We study both the restricted case where $D=D^{*}$ as well as the unrestricted case. We exclude the war years 1939 through 1945 from our sample.

When we define the technology measures as $m_{\tau} \in\left\{y_{\tau}, k_{\tau}\right\}$ then the unrestricted reduced form equation that we estimate can be written as

$$
\begin{aligned}
m_{\tau}= & \beta_{0}+y+\beta_{1}\left[(\mu-1) \ln \left(t-D-\mathbf{1}(t<1939) \Delta D-\underline{v}_{\tau}\right)-(1-\alpha)(y-l)\right] \\
& +\beta_{2}\left(t-D-\mathbf{1}(t<1939) \Delta D-\underline{v}_{\tau}\right)+\beta_{3} \Delta c+\beta_{4} X_{\tau} .
\end{aligned}
$$

This equation is derived in detail in Appendix A. Here $\mathbf{1}($.$) is an indicator function that is$ one if the condition holds and zero otherwise. The prewar adoption lag equals $D^{*}=D+\Delta D$. Finally, as we discussed above, we capture the transitional dynamics by the usercost term, $\beta_{3}$, and the adjustment cost term $\beta_{4}$.

\subsection{Estimation}

In principle, having data for many technologies and many countries, we can combine the country-technology equations and obtain a very large system of non-linear equations based on (25) to estimate. In practice, this turns out to be infeasible. Hence, instead of taking a system estimation approach, we estimate (25) for each country and technology separately. However, because (25) implies cross-country restrictions on the parameters, we do not do so in an unrestricted manner. We impose these cross-country restrictions by applying the

\footnotetext{
${ }^{21}$ The profit maximization problem subject to these adjustment costs that results in the inclusion of this term in our equations is described in the appendix.

${ }^{22}$ We assume that these costs are only present during the postwar recovery.
} 
U.S. estimates for all countries for the parameters that are assumed to be constant across countries. There are two parameters, $\mu$ and $\alpha$, which we do not estimate but for which we simply impose the calibrated parameter values used in Comin and Hobijn (2010), which are based on postwar U.S. evidence.

There is another advantage of this approach over a system estimation of the parameters. Because we apply this model to a very broad sample of countries and system estimation would be affected by serious misspecification of the model or measurement error in the data for each of these countries. Using this approach, we basically assume the model is properly specified and the data are relatively reliably measured for the United States to identify the common parameters across countries.

The cross-country parameter restrictions we impose across countries are based on the assumption that the technology parameters are the same across countries and that what potentially differs are adoption lags, preferences, and adjustment costs. This assumption means that $\beta_{1}$ and $\beta_{2}$ are the same across countries and that the other parameters can potentially vary. We estimate each equation using non-linear least squares.

Note that the parameter $\beta_{2}$ captures the linear trend in the diffusion process of technology and that we estimate a different trend for each technology. This trend captures a variety of elements including embodied and disembodied productivity growth and the evolution of demand for the technology as countries develop (i.e. the Engel curve). Since the trend is specific to each technology, it captures the substitution away from old technologies that eventually are dominated by a superior technology (e.g. telegrams). These dynamics will not be reflected in the estimates of the adoption lags, neither in the level (i.e. $D$ ) nor on the postwar change (i.e. $\triangle D$ ), which are identified through the curvature of the diffusion process.

It is also relevant for our analysis to discuss how variation in disembodied technological productivity, or in the size of the economy, affects our identified changes in the adoption lags. As can be seen from equations (20) and (25), changes in the disembodied part of TFP and 
the size of the economy do not affect the equilibrium adoption lags since they equally affect the costs and benefits of adoption. ${ }^{23}$ In fact, peristent changes in disembodied productivity do not even affect adoption lags much along the transitional path. This can be seen from the simulated transition path for a permanent upward shift in disembodied productivity plotted in Figure 4.

To induce some effects on our estimated adoption lags, we need to make the assumption that wages do not adjust temporarily to the increase in market size or in overall TFP. Incidentally, this assumption corresponds to the hypothesis presented in Eichengreen (2007) who argued that after WWII there was a change in the social contract in Europe which tempered unions' demands for wage increases despite the accelerating productivity. In that event, an increase in efficiency or market size shall have a larger effect on the revenues than in the costs of adopting and using new technologies leading to a temporary increase in our technology usage measure, $m_{\tau}$, and to a reduction in the diffusion lags. ${ }^{24}$ Note however, that this comparative dynamics would, to a first order, affect all the technologies symmetrically.

\section{Results}

We present our results in three parts. In the first part, we summarize the estimated changes in adoption lags that we obtained using the method described above. In the second part, we estimate the association between the change in the speed of adoption and several measures of U.S. postwar involvement. In the final part, we study the association between technology adoption and postwar growth.

\footnotetext{
${ }^{23}$ This equal effect of disembodied productivity on these costs and benefits is necessary for the model to have a balanced growth path with constant adoption lags.

${ }^{24}$ This argument can be formalized either by using the optimal adoption equation in the model (20) or by using the reduced form expression for the demand for our technology measures (23) or (24).
} 


\subsection{Estimated changes in the adoption lags}

The parameter estimates for the U.S. specification as well as for the level of the adoption lags, $D$, are very similar to those reported in Comin and Hobijn (2010). That study also shows that a simplified version of specification (25) fits the diffusion curves for a sample of technologies and countries that contains those in our sample well. Therefore, we focus our analysis on the estimated changes in the adoption lags.

Just like in (25) we use the convention that a positive change in the adoption lag reflects a increase in the speed of adoption. In this sense, we estimate the reduction in the adoption lag. In terms of the notation in (25), we estimate $\Delta D_{c \tau}$, where $c$ denotes the country and $\tau$ the technology.

In practice, we obtain several estimates of $\Delta D_{c \tau}$ because we use various specifications nested in (25) that differ in terms of the inclusion of the adoption costs and the user cost and in whether the adjustment cost parameter is restricted to equal to for the U.S. We do not need to take a stance on the right model specification. Instead, for each technologycountry pair, we compute the average reduction in the adoption lag across the different specifications. ${ }^{25}$

Table 2 provides summary statistics for our estimates of the reduction in the adoption lags after WWII. On average adoption lags decreased slightly after WWII in the sample of technologies and countries we analyze. There are significant differences across technologies. While 'new' technologies experienced a reduction in adoption lags of almost 4 years, 'old' technologies experienced an average increase in the adoption lags of 4 years.

There is significant variation in the changes in adoption lags even within our groups of technologies. For example, across old technologies, the average reduction in adoption lags varies from 13 years for steam and motor ships to an increase by 29 years for rail transportation of passengers. This might be problematic because of the unbalanced nature

\footnotetext{
${ }^{25}$ As in Comin and Hobijn (2010), we restrict attention to those estimates that are plausible and precise. See Comin and Hobijn (2010) for how we define these.
} 
of our panel of estimated declines in adoption lags. In particular, if the countries that received U.S. help over the postwar period are over-represented in our sample in technologies with increases in lags (e.g. railways) while countries that did not received U.S. help are overrepresented in technologies that experienced declines in lags (e.g. steam and motor ships), we could incorrectly conclude that U.S. help is associated with an increase in the adoption lags.

This example is actually a good description of the unbalance in our sample of estimates. We take care of this problem by including technology fixed effects in the regressions where we study the drivers or effects of adoption lags in new vs. old technologies.

In addition to the distinction between old and new technologies, we distinguish between technologies with and without a close predecessor. As argued in Comin and Hobijn (2009a), this distinction allows us to explore Mancur Olson's (1982) hypothesis that interest groups associated with incumbent technologies may slowdown the diffusion of a new superior technology. If this is the main driving force of the adoption lag reductions in our data then these reductions should be especially large for those technologies that were substituting a predecessor technology.

Key to the implementation of this test is the classification of new technologies between those that have and those that do not have a competing predecessor. Comin and Hobijn (2009a) use the relative productivity between new and incumbent technologies to conduct this classification. Table 2 reproduces the relative productivity of new technologies based on the micro studies surveyed in Comin and Hobijn (2009a). According to this classification, radio, trucks and cars have a competing predecessor while electricity, planes and telephone do not have a competing predecessor.

When classifying new technologies in these two groups, we find that technologies without a competing predecessor tended to experience larger reductions in adoption lags than those with one. In particular the lags of the former declined by almost 13 years, while those of the later increased on average by 5 years. Note that this is the opposite pattern one would 
expect if Olsonian incumbent dynamics were less prevalent after WWII.

\subsection{Effect of postwar U.S. assistance on adoption}

The first stage of our analysis involves analyzing whether the U.S. postwar involvement changed the adoption dynamics and did so differently for old and new technologies. We consider three measures of U.S. involvement. The first is a dummy that is equal to one if the country received significant U.S. assistance. That basically corresponds to those countries that participated in the Marshall Plan and to Japan. Second, we consider the total expenditure in the U.S. technology assistance program (TAP) in the country. Finally, we consider the total U.S. aid expenditures between 1948 and 1953.

Table 3 reports the estimates of the effect of the U.S. postwar involvement measures on the reduction in the lags after WWII. The main finding from our estimates, reported in columns I through III is that a larger U.S. involvement is associated with a larger reduction in the adoption lags for new technologies. This effect is considerable. The average country that received significant postwar U.S. assistance experienced a reduction in the lags with which new technologies were adopted of about 4.5 years. Similarly, a one standard deviation increase in the U.S. expenditure in either the technology assistance program or the Marshall plan is associated with a decline in the adoption lags of new technologies of approximately 2.5 years. the effects for old technologies are even larger.

In contrast, for old technologies we find that a larger U.S. involvement is associated with an increase in the adoption lags. These effects seem even larger than for new technologies. The average country that received significant postwar U.S. assistance experienced an increase in the lags with which new technologies were adopted of about 14 years.

One may wonder whether the effects of assistance on the adoption lags persist after controlling for any country-specific characteristic. To explore this, we re-run the regressions with country fixed effects. Since the assistance variables only have cross-country variation, this exercise only allows us to identify their differential effect on the reduction in the lags of 
new vs. old technologies. The results, reported in columns IV through VI, show that the effect of U.S. postwar assistance on adoption is very robust. Even after controlling for any possible country-specific factor, U.S. assistance is associated with a larger reduction in the adoption lags of new than old technologies. The average country that received significant postwar U.S. assistance experienced a reduction in the adoption lags of new technologies 16.5 years larger than in the lags of old ones.

This finding is relevant since most of the omitted variables that could be driving the association between the assistance programs and the reduction in adoption lags should, a priori, affect all technologies more or less symmetrically. Take the power of unions, for example. If, as argued by Eichengreen (2007), the foreign intervention leads to a new social contract that reduces union demands, this should enhance investment in all forms of capital, those that embody new technologies and those that embody old technologies. So, to a first order, we should observe that the effects of such policies be captured by the country fixed effect. The same is true for other changes that affect the size or efficiency of the economy such as the process of European integration or policies that lead to a more efficient bureaucracy, lower taxes, or less distorted markets. The fact that we are observing such a large and significant differential effect on the adoption lag of the new technologies leads us to believe that the driver of the effect of the assistance variables on the decline in adoption lags was not a general increase in efficiency.

Olson (1982) implies that the differential effect of the U.S. assistance in the diffusion of new technologies is due not to a transfer of technology but to a reduction of the power of incumbent producers. These producers might have used their power to raise barriers that slowdown the diffusion of new technologies before WWII. As their power weakened, new the diffusion of new technologies could have accelerated. Table 4 tests this hypothesis by estimating the differential effect of the U.S. assistance variables on the diffusion of new technologies with and without a close predecessor. Contrary to the Olsonian hypothesis, we find that technologies with a close predecessor did not experience a larger acceleration 
in diffusion than those without such close predecessors. This conclusion is robust to the inclusion of country fixed effects as shown in columns IV through VI.

Hence, we conclude a significant part of the postwar dynamics of technology diffusion we have uncovered can be explained by the U.S. assistance programs that resulted in a transfer of knowledge from the U.S. to other nations. This does not mean that the alternative driving forces we discussed did not contribute, it means that they do not match the cross-technology variation that we uncovered in the data.

\subsection{Effect of adoption on per capita GDP}

We conclude our analysis by exploring whether postwar reductions in adoption lags are associated with faster growth. We do that by estimating the following specification

$$
y_{1970 c}=\alpha+\rho * y_{1950 c}+\beta * \overline{\Delta D}_{c}+\epsilon_{c}
$$

where $y_{T c}$ denotes the log of per capita income in year $T$ in country $c, \overline{\Delta D}_{c}$ is the average reduction in adoption lags across technologies for country $c$, and $\epsilon_{c}$ is an error term.

In the first column of Table 5, we estimate the effect of the reduction in the new technologies adoption lags on $(\log )$ per capita income in 1970. We find that the reduction in the lag with which new technologies were adopted after WWII is significantly associated with faster postwar growth in per capita income. ${ }^{26}$ In particular, the reduction of an additional year in the avarage lag with which new technologies were adopted led to a 1 percent increase in per capita income in 1970. This implies that a one standard deviation decline in the adoption lags for new technologies is associated with an increase in the annual growth rate of per capita income of 0.65 percentage points between 1950 and 1970 .

In column II we estimate the growth effects of a reduction in the adoption lags of the old technologies. For these technologies, we find no significant growth effect associated with an

\footnotetext{
${ }^{26}$ This is consistent with Dowrick and Rogers' (2002) finding that allowing for technology catch-up significantly enhances the fit of conventional cross-country growth regressions.
} 
acceleration in their diffusion. Columns III through VI show that these findings are robust to controlling for postwar institutions and policies. In particular, they are robust to controlling for the initial competition in the political system as measured by Polity and to the degree of trade openness in the economy openness as measured by the ratio of exports plus imports over GDP. The results are also robust to controlling for the change in these variables between 1950 and 1970.

Hence, this suggests that the acceleration in the speed of diffusion of new technologies during the postwar period might have been a significant driver of the extraordinary growth performance of several western European countries and Japan.

\section{Conclusion}

In this paper we revisited the remarkable postwar growth experiences of Western European countries and Japan. In addition to considering the oft-studied gains in real GDP per capita, we also considered technology usage measures for ten technologies taken from Comin and Hobijn (2009b).

The evidence we presented showed that, in terms of real GDP per capita, these countries did not return to their prewar growth path. They, instead, moved up to a higher path than they were on before the war. This boost in growth was mainly driven by growth in Total Factor Productivity. It was also accompanied by commensurate increases in technology usage.

We introduced a version of the model of technology adoption and economic growth from Comin and Hobijn (2010) to translate these changes in the usage of these technologies into estimates of the acceleration in the speed of adoption of these technologies. We use this model to estimate changes in the time between the invention and adoption of 10 different technologies for 39 countries that occurred after WWII.

Our estimates reveal that good postwar growth performances relative to the U.S. hap- 
pened in countries that also saw a relatively large pickup in the speed of adoption of technologies that had been invented less than a century before the end of the war. For older technologies, this positive correlation between postwar catch-up and changes in adoption lags is not present.

We document that a substantial part of the cross-country variation in these changes in adoption lags can be explained by differences in the amount of postwar U.S. economic aid and technical assistance across countries. We interpret this is evidence of technology transfers from the U.S. to Western Europe and Japan being an important driving force of the impressive postwar growth performance by these recipients.

Of course, such technology transfers were probably not the sole driving force of the "supergrowth" that many countries experienced in the postwar period. Many studies, like for example Alvarez-Cuadrado and Pintea (2009), Eichengreen (2007), and Olson (1982), have proposed alternative explanations. None of these explanations, however, is consistent with the differential effect of the changes in the adoption of old and new technologies. This does not mean that they did not contribute to postwar catch-up in Western Europe and Japan, but it does mean that they can not account for the variation in technology adoption patterns that we have uncovered in the data. 


\section{References}

[1] Abramovitz, Moses (1986), "Catching Up, Forging Ahead, and Falling Behind," Journal of Economic History, 46 , 388-406.

[2] Acemoglu, Daron, Simon Johnson, and James A. Robinson (2001), "The Colonial Origins of Comparative Development: An Empirical Investigation," American Economic Review, 91, 1369-1401.

[3] Alvarez-Cuadrado, Francisco, and Pintea, Mihaela I. (2009) "A quantitative exploration of the Golden Age of European growth," Journal of Economic Dynamics and Control, $33,1437-1450$.

[4] Barro, Robert J., and José F. Ursúa (2008), "Macroeconomic Crises since 1870," Brookings Papers on Economic Activity, Spring 2008.

[5] Baumol, William J. (1986), "Productivity Growth, Convergence, and Welfare: What the Long-Run Data Show," American Economic Review, 76, 1072-1085.

[6] Bjarnar, Ove, and Matthias Kipping (1998), The Americanisation of European Business: The Marshall Plan and the Transfer of US Management Models, New York: Routledge.

[7] Boel, Brent (2003). The European Productivity Agency and Transatlantic Relations 1953-1961. Copenhagen, Denmark: Museum Tusculanum Press.

[8] Brynjolfsson, Erik, and Lorin M. Hitt (2000), "Beyond Computation: Information Technology, Organizational Transformation and Business Performance," Journal of Economic Perspectives, 14, 23-48.

[9] Cette, Gilbert, Yusuf Kocoglu, and Jacques Mairesse (2009), "Productivity Growth and Levels in France, Japan, the United Kingdom and the United States in the Twentieth Century," NBER Working Paper No. $1557 \%$. 
[10] Chen, Kaiji, Ayşe Imrohoroğlu, and Selahattin Imrohoroğlu (2006), "The Japanese Saving Rate," The American Economic Review, 96, 1850-1858

[11] Christiano, Lawrence J. (1989), "Understanding Japan's Saving Rate: The Reconstruction Hypothesis," Federal Reserve Bank ofMinneapolis Quarterly Review, 13, 10-25.

[12] Comin, Diego A., William Easterly and Erick Gong (2010), "Was the Wealth of nations Determined in 1000 BC?," American Economic Journal: Macroeconomics, forthcoming.

[13] Comin, Diego A., and Bart Hobijn (2009a), "Lobbies and Technology Diffusion," Review of Economics and Statistics, 91, 229-244.

[14] Comin, Diego A., and Bart Hobijn (2009b), "The CHAT Dataset," NBER Working Paper 15319 .

[15] Comin, Diego A., and Bart Hobijn (2010), "An Exploration of Technology Diffusion," American Economic Review, forthcoming.

[16] De Long, J. Bradford, and Barry Eichengreen (1991), "The Marshall Plan: History's Most Successful Structural Adjustment Program," mimeo, UC Berkeley.

[17] De Long, J. Bradford (1988), "Productivity Growth, Convergence, and Welfare: Comment," American Economic Review, 78, 1138-1154.

[18] Dowrick, Steve, and Mark Rogers (2002), "Classical and Technological Convergence: Beyond the Solow-Swan Growth Model," Oxford Economics Papers, 54, 369-385.

[19] Dumke, Rolf H. (1990), "Reassessing The Wirtshaftswunder: Reconstruction and Postwar Growth in West Germany in an International Context," Oxford Bulletin of Economics and Statistics, 52, 451-492.

[20] Eaton, Jonathan, and Samuel Kortum (1997), "Engines of growth: Domestic and foreign sources of innovation," Japan and the World Economy, 9,235-259. 
[21] Eichengreen, Barry J. (2007), The European Economy Since 1945: Coordinated Capitalism and Beyond, Princeton: Princeton University Press.

[22] Eichengreen, Barry J., and Marc Uzan (1992), "The Marshall Plan: Economic Effects and Implications for Eastern Europe and the Former USSR," Economic Policy, 7, 14-75.

[23] Gilchrist, Simon, and John C. Williams (2004), "Transition Dynamics in Vintage Capital Models: Explaining the Postwar Catch-Up of Germany and Japan," Federal Reserve Bank of San Francisco Working Paper 2004-14.

[24] Glick, Reuven, and Alan M. Taylor (2010), "Collateral Damage: Trade Disruptions and the Economic Impact of War," Review of Economics and Statistics, forthcoming.

[25] Hall, Robert E., and Charles I. Jones (1999), "Why Do Some Countries Produce So Much More Output per Worker than Others?" Quarterly Journal of Economics, 114(1): 83-116.

[26] Hayashi, Fumio (1986), "Why Is Japan's Saving Rate So Apparently High?" NBER Macroeconomics Annual, 1, Stanley Fischer (ed.), Cambridge, MA: MIT Press.

[27] Hayashi, Fumio (1989), "Is Japan's Saving Rate High?" Federal Reserve Bank of Minneapolis Quarterly Review, 13, 3-9.

[28] Hess, Gregory D., and Athanasios Orphanides (1995), "War Politics: An Economic, Rational-Voter Framework," American Economic Review, 85, 828-846.

[29] Heston, Alan, Robert Summers and Bettina Aten, (2009), Penn World Table Version 6.3, Center for International Comparisons of Production, Income and Prices at the University of Pennsylvania, August 2009.

[30] International Cooperation Administration (1958), European Productivity and Technical Assistance Programs: A Summing Up, 1948-1958, Paris. 
[31] Klenow, Peter J., and Andrés Rodríguez-Clare (1997), "The Neoclassical Revival in Growth Economics: Has It Gone Too Far?" NBER Macroeconomics Annual, 12: 73103.

[32] Maddison, Angus (2007), Contours of the World Economy 1-2030 AD: Essays in MacroEconomic History. Oxford: Oxford University Press.

[33] Miguel, Edward, Shanker Satyanath, and Ernest Sergenti (2004), "Economic Shocks and Civil Conflict: An Instrumental Variables Approach," Journal of Political Economy, $112,725-753$.

[34] Olson, Mancur (1982), The Rise and Decline of Nations, New Haven: Yale University Press.

[35] Parente, Stephen L., and Edward C. Prescott, (1994), "Barriers to Technology Adoption and Development." Journal of Political Economy, 102(2): 298-321.

[36] Prescott, Edward C. (1997), "Needed: A theory of total factor productivity," International Economic Review, 39, 525-551.

[37] Solow, Robert M. (1960), "Investment and Technical Progress," in Mathematical Methods in the Social Sciences, Kenneth J. Arrow, Samuel Karlin and Patrick Suppes, (eds), Stanford: Stanford Univ. Press.

[38] Saint James Press (2001), International Directory of Company Histories, London: Saint James Press.

[39] Tiratsoo, Nick (2000), "The United States Techincal Assistance Programme in Japan, 1955-62," Business History, 42, 117-136.

[40] Van Ark, Bart, and Dirk Pilat (1993), "Productivity Levels in Germany, Japan, and the United States: Differences and Causes," Brookings Papers on Economic Activity. Microeconomics, 1993-2, 1-69. 
[41] Wasser, Solidelle F., and Micheal L. Dolfman (2005), "BLS and the Marshall Plan: The Forgotten Story," Monthly Labor Review, 128(6), 44-52.

[42] Wolff, Edward N. (1991), "Capital Formation and Productivity Convergence over the Long-Term," American Economic Review, 81,565-79. 


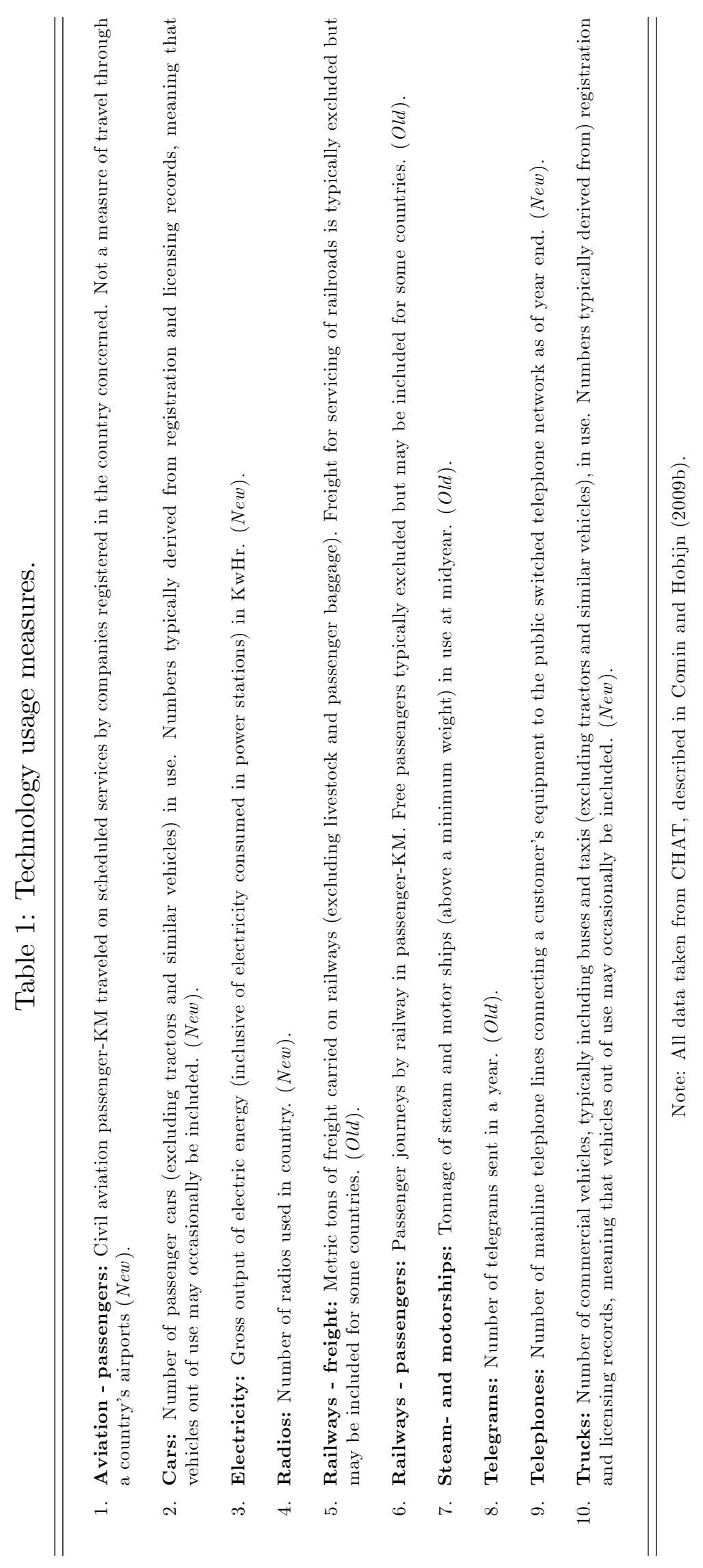




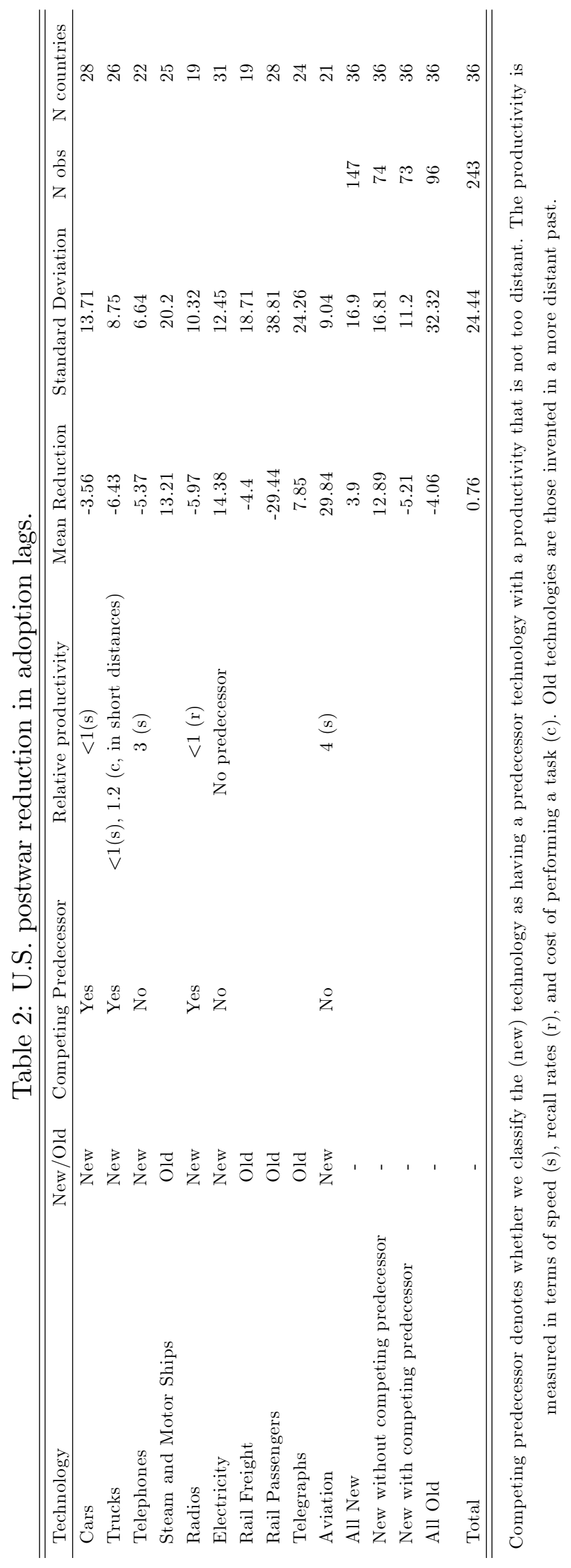




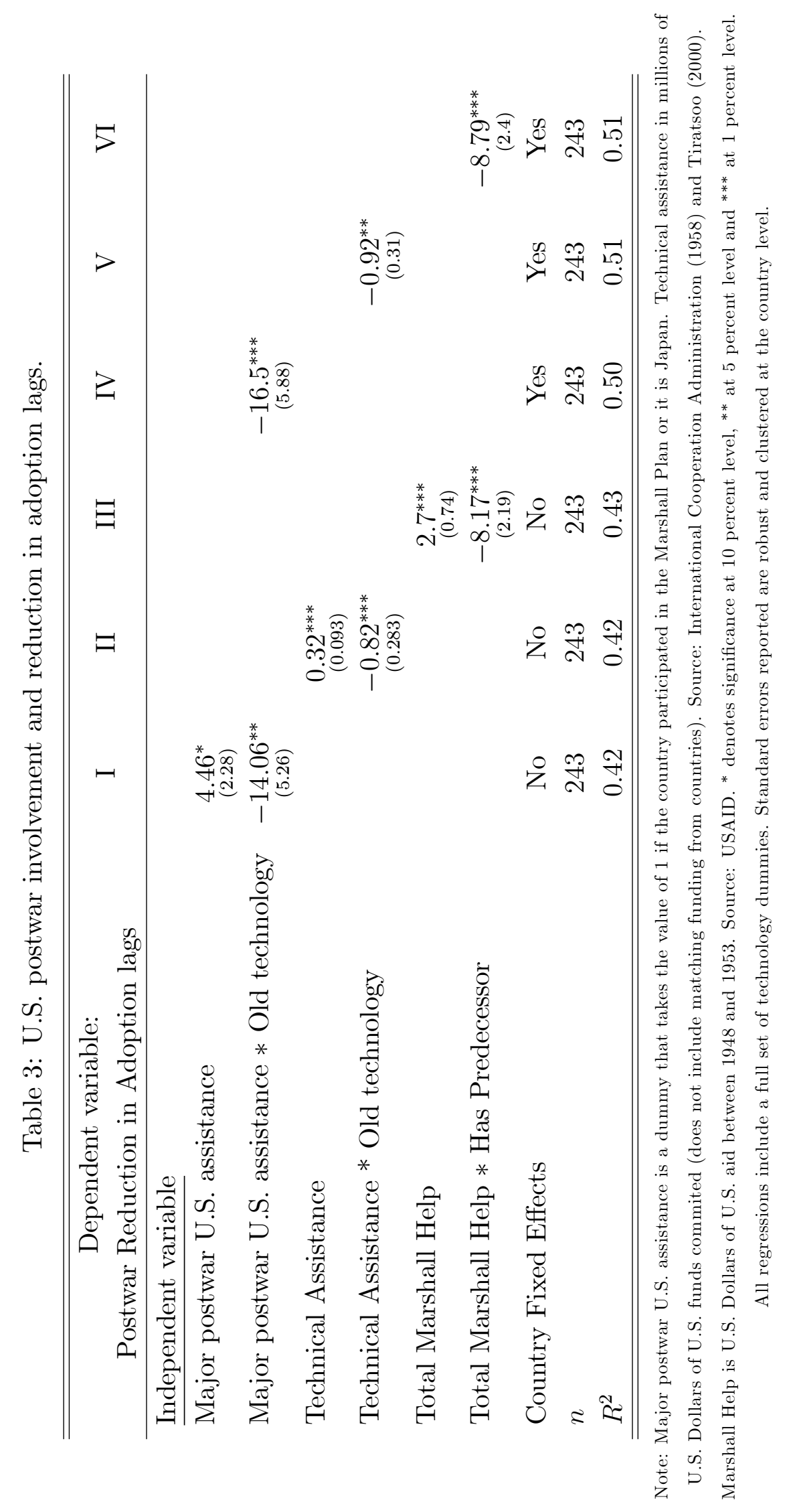




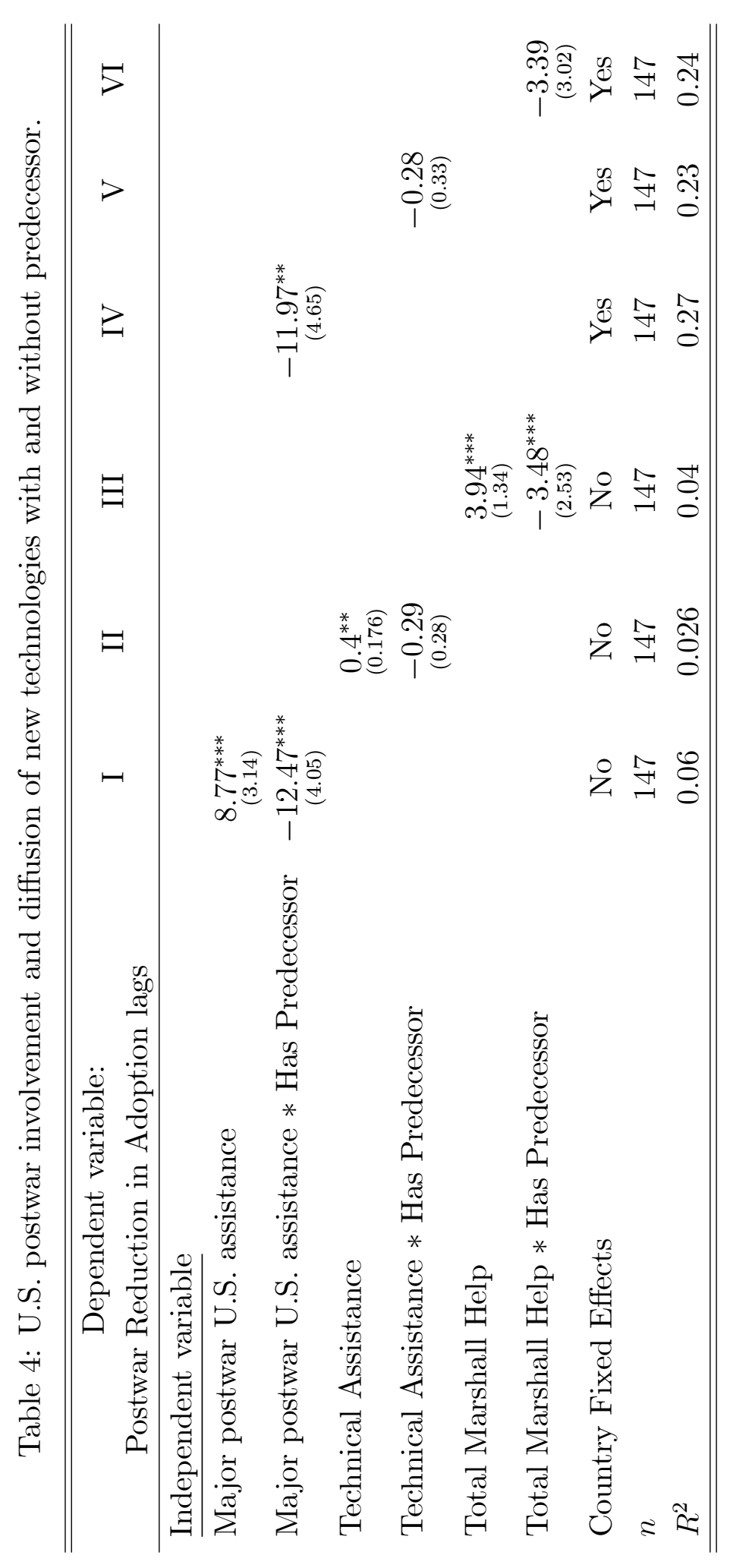

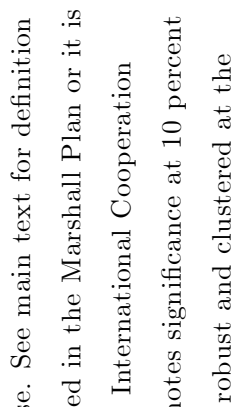

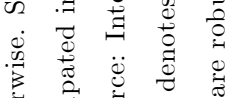

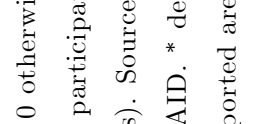

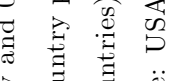

bे

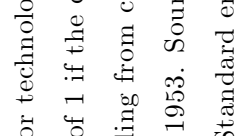

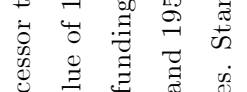

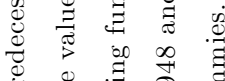

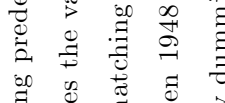

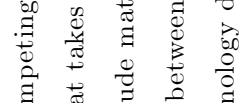

吾

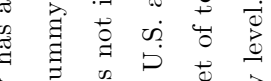

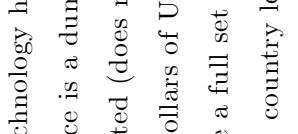

Ð

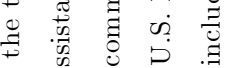

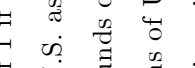

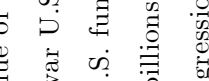

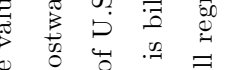

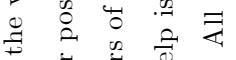

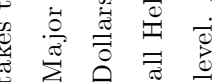

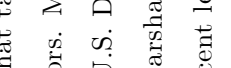

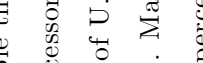

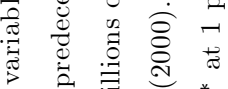

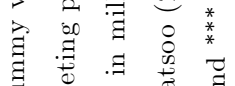

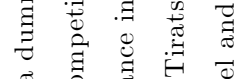

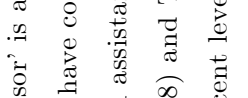

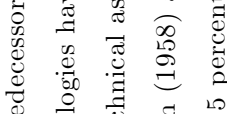

$\begin{array}{lllll}0 & 0 & 0 & 0 & 0 \\ 0 & 0 & 0 & 0 \\ 0 & 0 & 0 & 0 & 0 \\ 0 & 0 & 0\end{array}$

芠

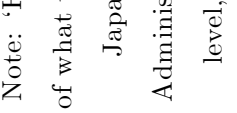




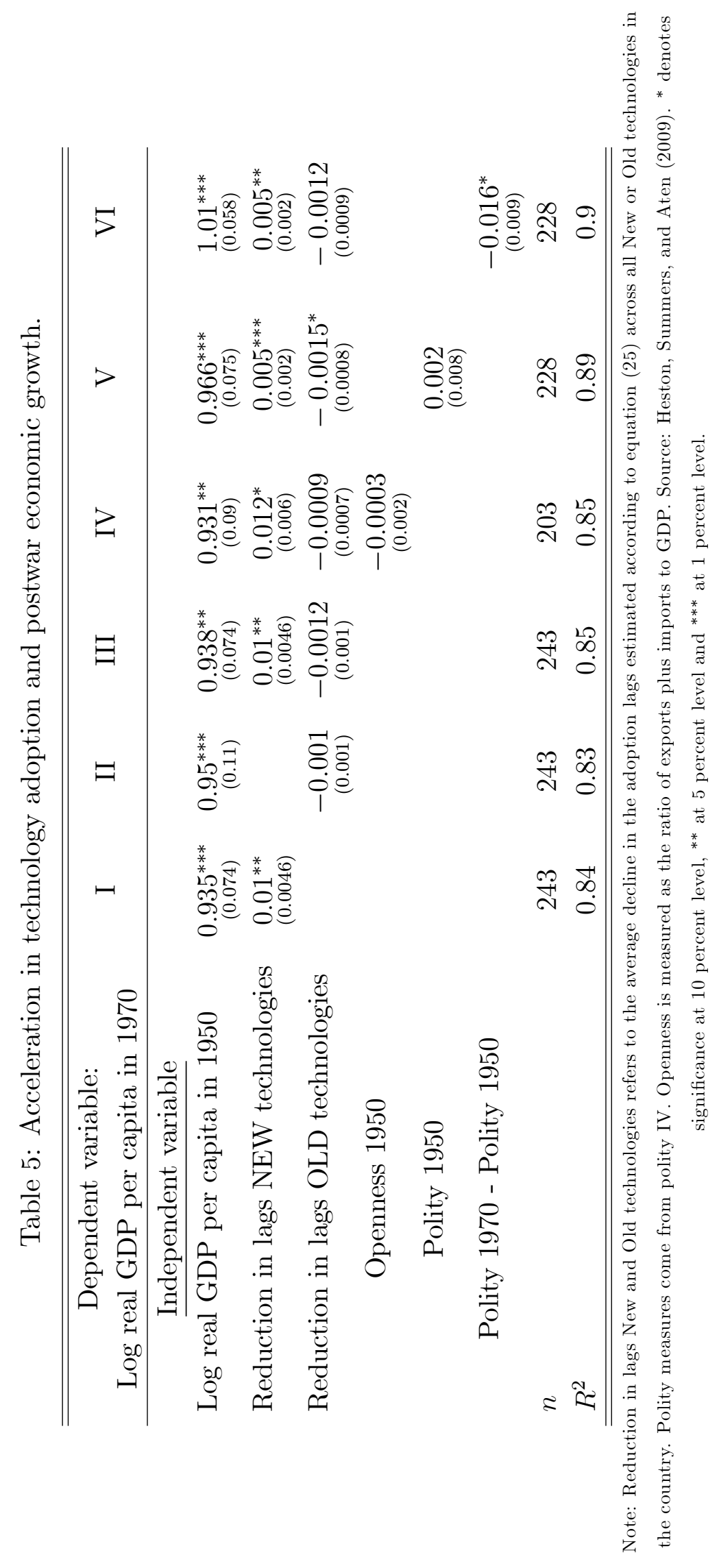



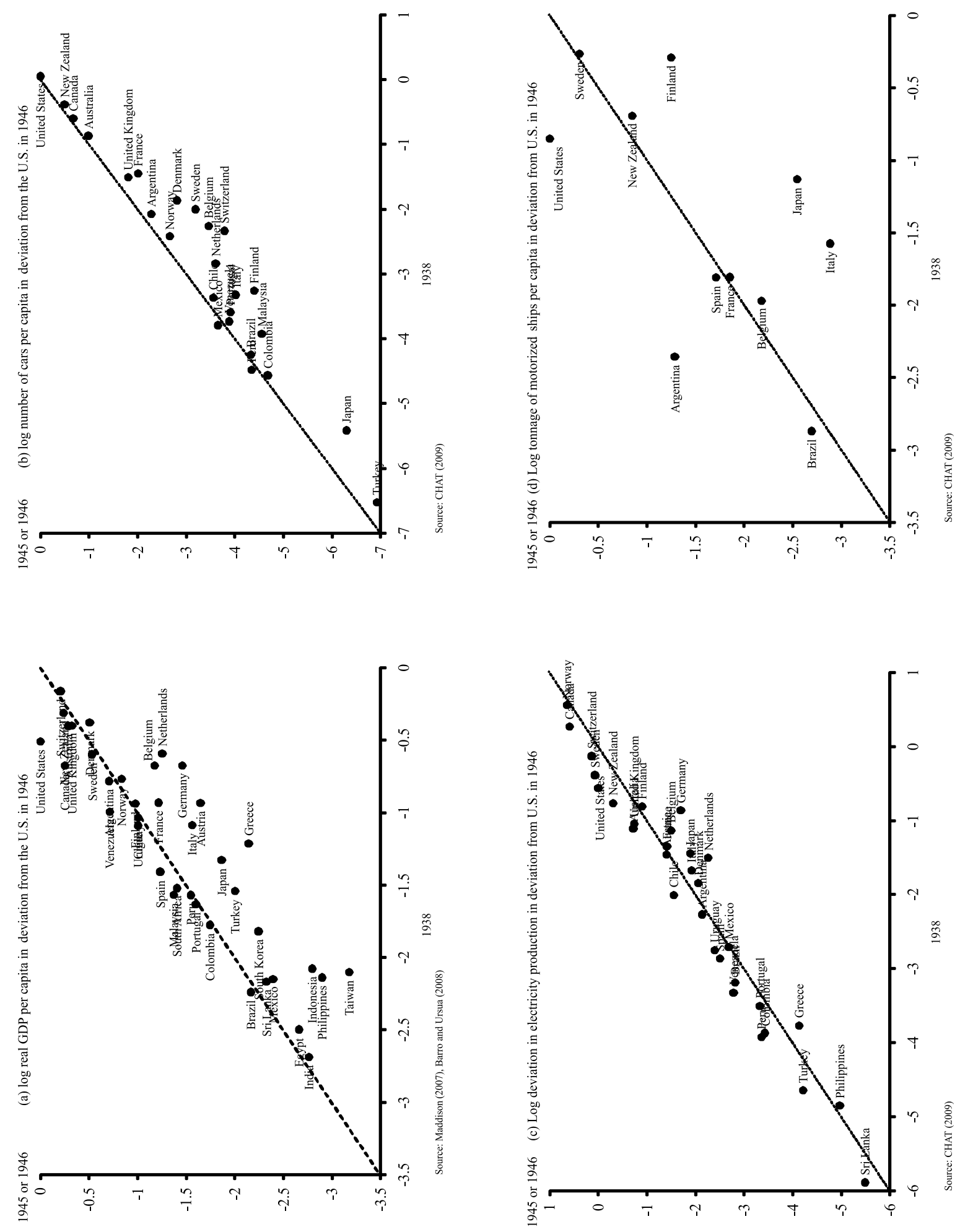

Figure 1: Changes in real GDP and technology usage per capita during WWII period. 

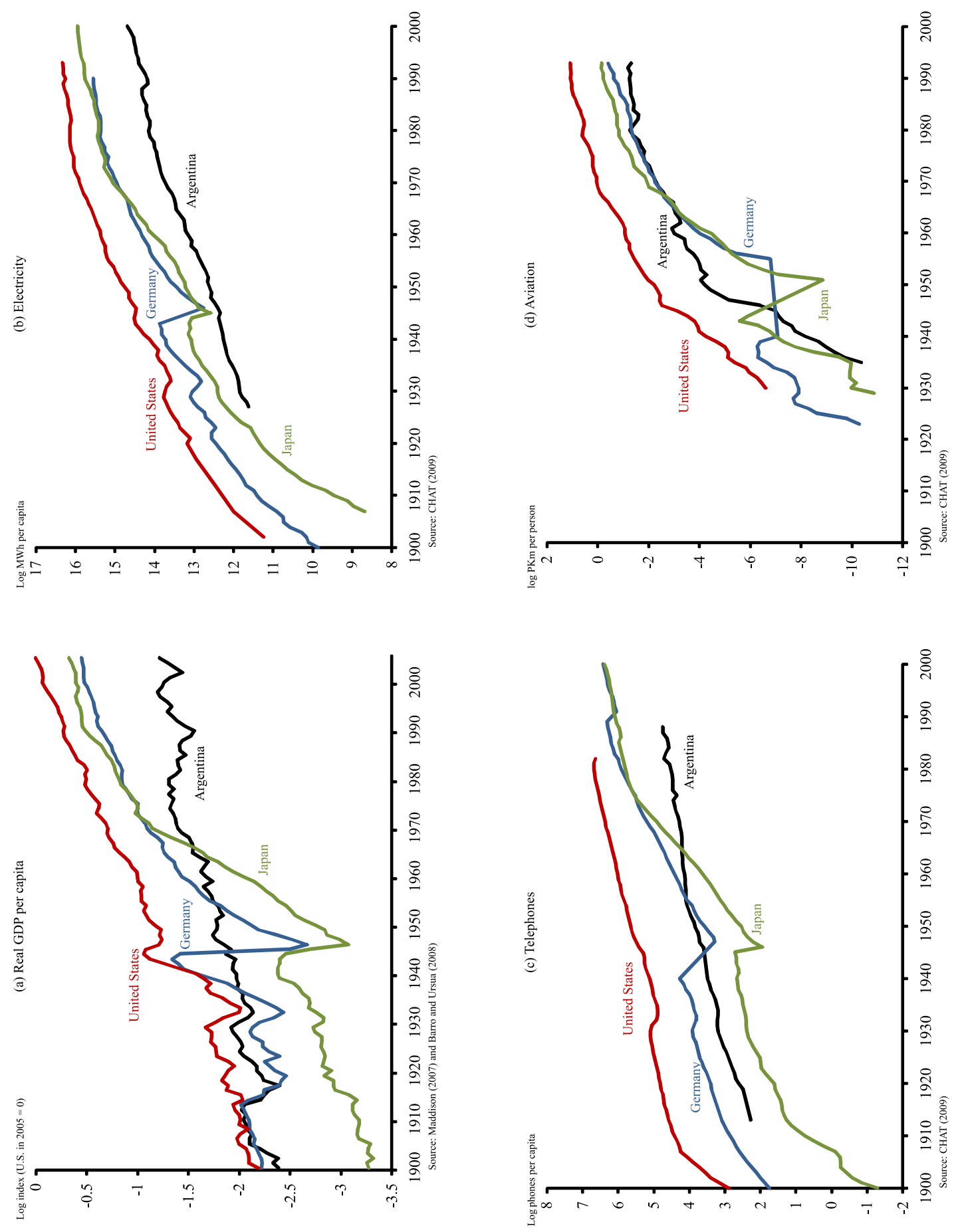

Figure 2: Real GDP and technology usage per capita for four countries 


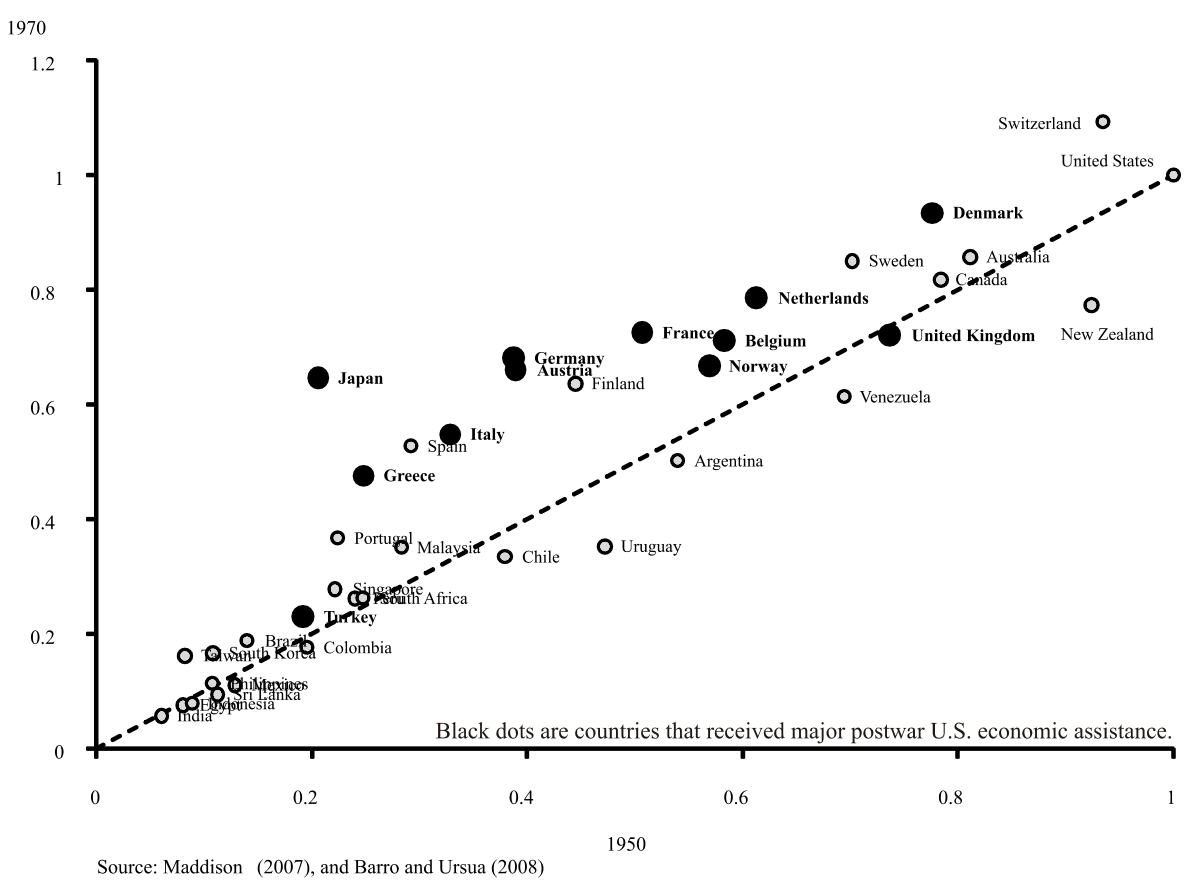

Figure 3: Postwar catch-up in real GDP per capita.

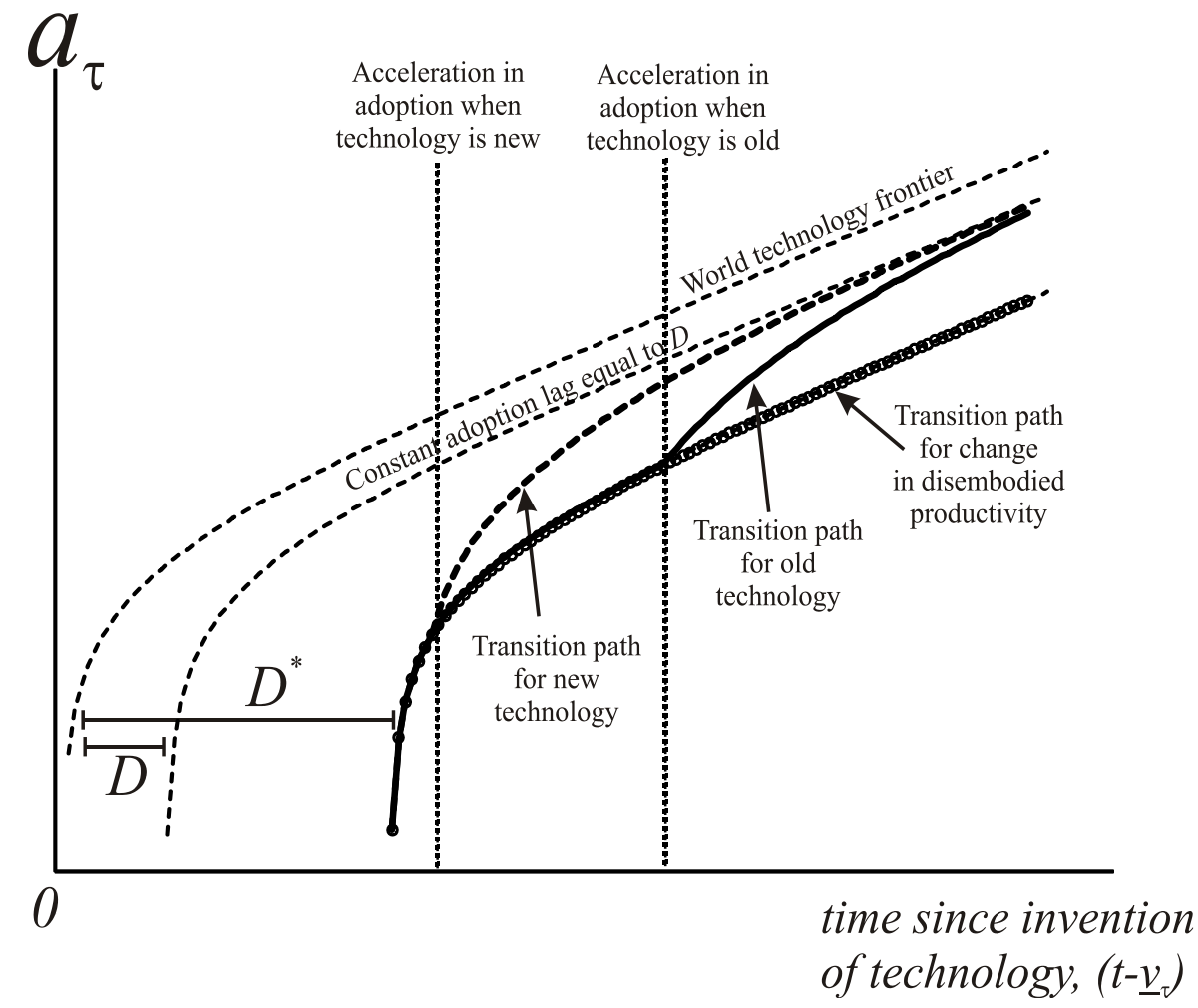

Figure 4: Path of technology-specific TFP under different scenarios. 


\section{A Online Appendix: Mathematical derivations}

This appendix contains mathematical details behind the equations presented in the main text. Because the model we use is based on the one introduced in Comin and Hobijn (2010), the derivations here are, in many respects, similar to the ones in that study. The main difference is the explicit introduction of adoption lags, $D_{t}$, as a state variable and the derivation of the resulting dynamics. Equations and results are derived in the order they appear in the main text.

\section{Derivation of equation (8):}

The demand for capital of a particular vintage is given by the factor demand equation

$$
R_{v} K_{v}=\alpha P_{v} Y_{v}
$$

Since revenue generated from the output produced with the vintage is determined by the demand function (6), we can write

$$
R_{v} K_{v}=\alpha Y P^{\frac{\mu}{\mu-1}} P_{v}^{-\frac{1}{\mu-1}} .
$$

Moreover, the price of the output produced with this vintage is given by the equilibrium unit production cost, such that we can write

$$
R_{v} K_{v}=\alpha Y Z_{v}^{\frac{1}{\mu-1}}\left(\frac{(1-\alpha)}{W}\right)^{\frac{1-\alpha}{\mu-1}}\left(\frac{\alpha}{R_{v}}\right)^{\frac{\alpha}{\mu-1}}
$$

such that

$$
K_{v}=Y_{\tau} Z_{v}^{\frac{1}{\mu-1}}\left(\frac{(1-\alpha)}{W}\right)^{\frac{1-\alpha}{\mu-1}}\left(\frac{\alpha}{R_{v}}\right)^{\epsilon}
$$

where

$$
\epsilon=\frac{\mu}{\mu-1}-\frac{1-\alpha}{\mu-1}=1+\frac{\alpha}{\mu-1},
$$

The Lagrangian associated with the dynamic profit maximization problem of the supplier of capital good $v$ at time $t$ equals

$$
\mathcal{L}_{v t}=\int_{t}^{\infty} e^{-\int_{t}^{s} \widetilde{r}_{s^{\prime}} d s^{\prime}} H_{v s} d s,
$$


where $H_{v s}$ is the current value Hamiltonian. We will drop the time subscript $s$ in what follows. Here

$$
\begin{aligned}
H_{v}= & \left(R_{v} K_{v}-Q I_{v}\right)+ \\
& \lambda_{v}\left(R_{v} K_{v}-\alpha Y Z_{v}^{\frac{1}{\mu-1}}\left(\frac{(1-\alpha)}{W}\right)^{\frac{1-\alpha}{\mu-1}}\left(\frac{\alpha}{R_{v}}\right)^{\epsilon-1}\right)+ \\
& \nu_{v}\left(I_{v}-\delta K_{v}\right) .
\end{aligned}
$$

Here $\lambda_{v}$ is the co-state variable associated with the demand function that the capital goods supplier faces and $\nu_{v}$ is the co-state variable associated with the capital accumulation equation.

The resulting optimality conditions read

$$
\begin{array}{cc}
\text { w.r.t. } R_{v}: & \left(1+\lambda_{v}\right) K_{v}+(\epsilon-1) \lambda_{v} K_{v}=0 . \\
\text { w.r.t. } I_{v}: & \nu_{v}=1 . \\
\text { w.r.t. } K_{v}: & \left(1+\lambda_{v}\right) R_{v}-\delta \nu_{v}=\widetilde{r} \nu_{v}-\dot{\nu}_{v} .
\end{array}
$$

The first optimality condition yields that

$$
\lambda_{v}=-\frac{1}{\epsilon}
$$

while the second and third yield that

$$
\begin{aligned}
R_{v} & =\frac{1}{\left(1+\lambda_{v}\right)}(\widetilde{r}+\delta) \\
& =\frac{\epsilon}{\epsilon-1}(\widetilde{r}+\delta)=R,
\end{aligned}
$$

which is $(8)$. Note that the resulting flow profits satisfy

$$
\pi_{v}=\frac{1}{\epsilon-1}(\widetilde{r}+\delta) K_{v}=\frac{1}{\epsilon} R K_{v}=\frac{\alpha}{\epsilon} P_{v} Y_{v}
$$

\section{Derivation of intermediate technology aggregation results:}

The price of intermediates produced with capital goods of vintage $v$ and the aggregate price level equal the unit production cost

$$
P_{v}=\frac{1}{Z_{v}}\left(\frac{W}{1-\alpha}\right)^{1-\alpha}\left(\frac{R}{\alpha}\right)^{\alpha} \text { and } P=\frac{1}{A}\left(\frac{W}{1-\alpha}\right)^{1-\alpha}\left(\frac{R}{\alpha}\right)^{\alpha}
$$

As a consequence, the relative price of output produced with vintage $v$ is given by the relative TFP level, 
i.e.

$$
\frac{P_{v}}{P}=P_{v}=\frac{A}{Z_{v}}
$$

where $P=1$ is the price of the numeraire good. The factor demands for each of the vintage specific output types satisfy

$$
W L_{\tau}=W \int_{v \in V_{\tau}} L_{v} d v=(1-\alpha) \int_{v \in V_{\tau}} P_{v} Y_{v} d v=(1-\alpha) P_{\tau} Y_{\tau}
$$

and

$$
R K_{\tau}=R \int_{v \in V_{\tau}} K_{v \tau} d v=\alpha \int_{v \in V_{\tau}} P_{v} Y_{v} d v=\alpha P_{\tau} Y_{\tau}
$$

Hence relative factor demands are the same as relative revenue levels

$$
\frac{P_{v} Y_{v}}{P_{\tau} Y_{\tau}}=\left(\frac{Y_{v}}{Y_{\tau}}\right)^{\frac{1}{\mu}}=\frac{L_{v}}{L_{\tau}}=\frac{K_{v}}{K_{\tau}}
$$

which allows us to write

$$
\begin{aligned}
Y_{v} & =Z_{v} K_{v}^{\alpha} L_{v}^{1-\alpha}=Z_{v}\left(\frac{Y_{v}}{Y_{\tau}}\right)^{\frac{1}{\mu}} K_{\tau}^{\alpha} L_{\tau}^{1-\alpha} \\
& =\left(Z_{v}\right)^{\frac{\mu}{\mu-1}}\left(\frac{1}{Y_{\tau}}\right)^{\frac{1}{\mu}}\left(K_{\tau}^{\alpha} L_{\tau}^{1-\alpha}\right)^{\frac{\mu}{\mu-1}} .
\end{aligned}
$$

We obtain that

$$
\begin{aligned}
Y_{\tau} & =\left(\int_{v \in V_{\tau}} Y_{v}^{\frac{1}{\mu}} d v\right)^{\mu}=\left(\int_{v \in V_{\tau}} Z_{v}^{\frac{1}{\mu-1}} d v\right)^{\mu}\left(\frac{1}{Y_{\tau}}\right)^{\frac{1}{\mu}}\left(K_{\tau}^{\alpha} L_{\tau}^{1-\alpha}\right)^{\frac{\mu}{\mu-1}} \\
& =\left(\int_{v \in V_{\tau}} Z_{v}^{\frac{1}{\mu-1}} d v\right)^{\mu-1}\left(K_{\tau}^{\alpha} L_{\tau}^{1-\alpha}\right)=A_{\tau} K_{\tau}^{\alpha} L_{\tau}^{1-\alpha} .
\end{aligned}
$$

The value of the unit production cost follows from the unit production cost of a Cobb-Douglas production function. The aggregation results at the highest level of aggregation can be derived in a similar way.

\section{Derivation of equation (16):}

This follows from

$$
\begin{aligned}
A_{n} & =\left(\int_{v \in V_{n}} Z_{v \tau}^{\frac{1}{\mu-1}} d v\right)^{\mu-1}=\left(\int_{\underline{v}}^{t-D_{t}}\left(Z_{\underline{v}} e^{\gamma(v-\underline{v})}\right)^{\frac{1}{\mu-1}} d v\right)^{\mu-1} \\
& =Z_{\underline{v}}\left(\int_{\underline{v}}^{t-D_{t}} e^{\frac{\gamma}{\mu-1}(v-\underline{v})} d v\right)^{\mu-1}=\left(\frac{\mu-1}{\gamma}\right)^{\mu-1} Z_{\underline{v}} e^{\gamma\left(t-D_{t}-\underline{v}\right)}\left[1-e^{-\frac{\gamma}{\mu-1}\left(t-D_{t}-\underline{v}\right)}\right]^{\mu-1} .
\end{aligned}
$$

Derivation of aggregate TFP, (17): 
This allows us to write aggregate total factor productivity as

$$
\begin{aligned}
A_{t} & =\left(\int_{-\infty}^{t-D_{t}} Z_{v}^{\frac{1}{\mu-1}} d v\right)^{\mu-1}=Z_{0}\left(\int_{-\infty}^{t-D_{t}} e^{\frac{\gamma}{\mu-1} v} d v\right)^{\mu-1} \\
& =Z_{0}\left(\frac{\mu-1}{\gamma}\right)^{\mu-1} e^{\gamma\left(t-D_{t}\right)}=A_{0} e^{\gamma\left(t-D_{t}\right)}
\end{aligned}
$$

\section{Derivation of equation (19):}

From the demand function we obtain that the revenue from output produced with capital goods of vintage $v$ is given by

$$
P_{v} Y_{v}=\left(\frac{P}{P_{v}}\right)^{\frac{1}{\mu-1}} Y=\left(\frac{Z_{v}}{A}\right)^{\frac{1}{\mu-1}} Y .
$$

The flow profits that the capital goods producer of vintage $v$ makes are equal to

$$
\pi_{v}=\frac{\alpha}{\epsilon} P_{v} Y_{v}=\frac{\alpha}{\epsilon}\left(\frac{Z_{v}}{A}\right)^{\frac{1}{\mu-1}} Y .
$$

This means that the market value of each of the capital goods suppliers of vintage $v$, at time $t$ equals the present discounted value of the above flow profits. That is,

$$
\begin{aligned}
M_{v, t} & =\int_{t}^{\infty} e^{-\int_{t}^{s} \widetilde{r}_{s^{\prime}} d s^{\prime}} \pi_{v s} d s \\
& =\left(\frac{Z_{v}}{A_{t}}\right)^{\frac{1}{\mu-1}} \frac{\alpha}{\epsilon} \int_{t}^{\infty} e^{-\int_{t}^{s} \widetilde{r}_{s^{\prime}} d s^{\prime}}\left(\frac{A_{t}}{A_{s}}\right)^{\frac{1}{\mu-1}} Y_{s} d s \\
& =\left(\frac{Z_{v}}{A_{t}}\right)^{\frac{1}{\mu-1}}\left[\frac{\alpha}{\epsilon} \int_{t}^{\infty} e^{-\int_{t}^{s} \widetilde{r}_{s^{\prime}} d s^{\prime}}\left(\frac{A_{t}}{A_{s}}\right)^{\frac{1}{\mu-1}} \frac{Y_{s}}{Y_{t}} d s\right] Y_{t} \\
& =\left(\frac{Z_{v}}{A_{t}}\right)^{\frac{1}{\mu-1}} \Psi_{t} Y_{t} .
\end{aligned}
$$

Here,

$$
\Psi_{t}=\left[\int_{-\infty}^{\bar{v}_{t}} M_{v, t} d v\right] / Y_{t}
$$

is the total market value of all monopolistic competitors.

\section{Derivation of equilibrium adoption lag, (20):}

The optimal adoption of technology vintages implies that the best vintage adopted at each instant satisfies

$$
\Gamma_{v}=M_{v}
$$


The adoption costs satisfy

$$
\Gamma_{v, t+d t}=e^{\chi b} \bar{\Psi}\left(\frac{\gamma}{\mu-1}\right)\left\{\frac{1}{\gamma} \frac{\frac{Z_{\bar{v}_{t}+d t}-Z_{\bar{v}_{t}}}{d t}}{Z_{\bar{v}_{t}}}\right\}\left(\frac{Z_{\bar{v}_{t}}}{Z_{t}}\right)^{\chi} Y_{t} .
$$

Taking the limit for $d t \downarrow 0$, we find that

$$
\begin{aligned}
\Gamma_{\bar{v}_{t}, t} & =e^{\chi b} \bar{\Psi}\left(\frac{\gamma}{\mu-1}\right)\left(\frac{Z_{\bar{v}_{t}}}{Z_{t}}\right)^{\chi}\left\{\dot{\bar{v}}_{t}\right\}^{\frac{1}{\mu-1}} Y_{t} \\
& =e^{\chi b} \bar{\Psi}\left(\frac{\gamma}{\mu-1}\right) e^{-\chi \gamma D_{t}}\left\{1-\dot{D}_{t}\right\}^{\frac{1}{\mu-1}} Y_{t}
\end{aligned}
$$

Moreover, note that

$$
M_{\bar{v}_{t}, t}=\left(\frac{Z_{\bar{v}_{t}}}{A_{t}}\right)^{\frac{1}{\mu-1}} \Psi_{t} Y_{t}=\left(\frac{\gamma}{\mu-1}\right) \Psi_{t} Y_{t}
$$

Combining this with the market value of the capital goods supplier of capital good $v$, we obtain that entry in the market determines that the path of the adoption lag satisfies.

$$
\bar{\Psi}\left(\frac{\gamma}{\mu-1}\right) e^{\chi b} e^{-\chi \gamma D_{t}}\left\{1-\dot{D}_{t}\right\} Y_{t}=\left(\frac{\gamma}{\mu-1}\right) \Psi_{t} Y_{t}
$$

Rearranging this yields that

$$
\dot{D}_{t}=1-\left[\frac{\Psi_{t}}{\bar{\Psi}}\right] e^{\chi\left(\gamma D_{t}-b\right)}
$$

which is $(20)$.

\section{Derivation of aggregate adoption costs, (21):}

From (56), it can be seen that, in equilibrium, the adoption costs equal

$$
\Gamma_{t}=\bar{\Psi}\left(\frac{\gamma}{\mu-1}\right) e^{-\chi\left(\gamma D_{t}-b\right)}\left\{1-\dot{D}_{t}\right\} Y_{t}
$$

Since

$$
1-\dot{D}_{t}=\left[\frac{\Psi_{t}}{\bar{\Psi}}\right] e^{\chi\left(\gamma D_{t}-b\right)}
$$

this simplifies to equation (21) in the main text.

\section{Equilibrium:}

Equilibrium is a path of the variables $\{C, K, I, \Gamma, Y, A, D, \Psi\}$ that satisfies the following equations: The consumption Euler equation

$$
\frac{\dot{C}_{t}}{C_{t}}=\left(\alpha \frac{\epsilon-1}{\epsilon} \frac{Y_{t}}{K_{t}}-\delta-\rho\right)
$$


where we have used that the real interest rate is related to the marginal product of capital as follows;

$$
\widetilde{r}_{t}=\alpha \frac{\epsilon-1}{\epsilon} \frac{Y_{t}}{K_{t}}
$$

The resource constraint

$$
Y_{t}=C_{t}+I_{t}+\Gamma_{t}
$$

The capital accumulation equation

$$
\dot{K}_{t}=-\delta K_{t}+I_{t} ;
$$

The production function

$$
Y_{t}=A_{t} K_{t}^{\alpha}
$$

The aggregate TFP equation

$$
A_{t}=A_{0} e^{\gamma \bar{v}_{t}}
$$

The adoption cost equation

$$
\Gamma_{t}=\left(\frac{\gamma}{\mu-1}\right) \Psi_{t} Y_{t}
$$

The adoption lag equation

$$
\dot{D}_{t}=1-\left[\frac{\Psi_{t}}{\bar{\Psi}}\right]^{\mu-1} e^{\chi\left(\gamma D_{t}-b\right)}
$$

And the market value equation

$$
\Psi_{t}=\frac{\alpha}{\epsilon} \int_{t}^{\infty} e^{-\int_{t}^{s} \widetilde{r}_{s^{\prime}} d s^{\prime}}\left(\frac{A_{t}}{A_{s}}\right)^{\frac{1}{\mu-1}} \frac{Y_{s}}{Y_{t}} d s
$$

which is best written in changes over time

$$
\frac{\dot{\Psi}_{t}}{\Psi_{t}}=\left\{\alpha \frac{\epsilon-1}{\epsilon} \frac{Y_{t}}{K_{t}}-\delta+\frac{1}{\mu-1} \frac{\dot{A}_{t}}{A_{t}}-\frac{\dot{Y}_{t}}{Y_{t}}\right\}-\frac{\alpha}{\epsilon} \frac{1}{\Psi_{t}}
$$

\section{Calibration of $\chi$ :}

Our model implies that

$$
a_{t}=a_{0}+\gamma\left(t-D_{t}\right) .
$$


Taking time-derivatives of this equation yields that

$$
\dot{a}_{t}=\gamma-\gamma D_{t} .
$$

Given (17) and (20) this can be written as

$$
\dot{a}_{t}=\gamma\left[\frac{\Psi_{t}}{\bar{\Psi}}\right] e^{-\chi b}\left(\frac{A_{t}}{A_{t}^{*}}\right)^{\chi},
$$

where $A_{t}^{*}=A_{t} \exp (\gamma t)$ is the world technology frontier. In this case $\chi$ corresponds to the parameter $s$ in Benhabib and Spiegel's (2006) general specification.

\section{Log-linearization of $a_{n}$ :}

Denote the adoption time by $T_{\tau}=D_{\tau}+\underline{v}_{\tau}$. Consider the technology-specific TFP level

$$
A_{n}=Z_{\underline{v}}\left[\left(\frac{\mu-1}{\gamma}\right)\left(e^{\frac{\gamma}{\mu-1}(t-D-\underline{v})}-1\right)\right]^{\mu-1}
$$

We are interested in the behavior of this TFP for $\gamma \downarrow 0$. In that case, there is no embodied productivity growth and the increase in productivity after the introduction of the technology is all due to the introduction of an increasing number of varieties over time.

For this reason, we consider

$$
\lim _{\gamma \downarrow 0} Z_{\underline{v}}\left[\left(\frac{\mu-1}{\gamma}\right)\left(e^{\frac{\gamma}{\mu-1}(t-D-\underline{v})}-1\right)\right]^{\mu-1}
$$

which, using de l'Hopital's rule, can be shown to equal

$$
Z_{\underline{v}}\left[\lim _{\gamma \downarrow 0}\left(\frac{\mu-1}{\gamma}\right)\left(e^{\frac{\gamma}{\mu-1}(t-D-\underline{v})}-1\right)\right]^{\mu-1}=Z_{\underline{v}}(t-D-\underline{v})^{(\mu-1)} .
$$


Taking the first order Taylor approximation around $\gamma=0$ yields that

$$
\begin{aligned}
A_{n} \approx & Z_{\underline{v}}(t-D-\underline{v})^{(\mu-1)}+ \\
& +Z_{\underline{v}}(t-D-\underline{v})^{(\mu-2)} \gamma \times \\
& {\left[\lim _{\gamma_{\tau} \downarrow 0}\left(\left(\frac{\mu-1}{\gamma}\right)(t-D-\underline{v}) e^{\frac{\gamma}{\mu-1}(t-D-\underline{v})}-\left(\frac{\mu-1}{\gamma}\right)^{2}\left(e^{\frac{\gamma}{\mu-1}(t-D-\underline{v})}-1\right)\right)\right] } \\
= & Z_{\underline{v}}(t-D-\underline{v})^{(\mu-1)}+ \\
& +Z_{\underline{v}}\left[\lim _{\gamma \downarrow 0}\left(\frac{\mu-1}{\gamma}\right)^{2}\left(\left(\frac{\gamma}{\mu-1}(t-D-\underline{v})-1\right) e^{\frac{\gamma}{\mu-1}(t-D-\underline{v})}+1\right)\right](t-D-\underline{v})^{(\mu-2)} \gamma \\
= & \left.Z_{\underline{v}}\left(t-T_{\tau}\right)^{(\mu-1)}\right](t-D-\underline{v})^{(\mu-2)} \gamma \\
& +Z_{\underline{v}}\left[\lim _{\gamma}(\mu-1)^{2} \frac{\gamma}{(\mu-1)^{2}}(t-D-\underline{v})^{2} e^{-\frac{\gamma}{\mu-1}(t-D-\underline{v})}\right] \\
= & Z_{\underline{v}}(t-D-\underline{v})^{(\mu-1)}+\frac{1}{2} Z_{\underline{v}}(t-D-\underline{v})^{\mu} \gamma \\
= & Z_{\underline{v}}(t-D-\underline{v})^{(\mu-1)}\left[1+\frac{1}{2}(t-D-\underline{v}) \gamma\right] .
\end{aligned}
$$

Hence, for $\gamma$ close to zero, we can use the log-linear approximation

$$
a_{n} \approx z_{\underline{v}}+(\mu-1) \ln (t-D-\underline{v})+\frac{\gamma}{2}(t-D-\underline{v}) .
$$

\section{Change in $D$ :}

However, our aim is to estimate how $D$ changes in response to the technical assistance provided by the U.S. after WWII. For this purpose, we allow for the following time-varying path of $D$.

$$
D_{t}=\left\{\begin{array}{cc}
D^{*}=D-\Delta D & \text { for } t<1939 \\
D & \text { for } t>1945
\end{array}\right. \text {, }
$$

where we are agnostic about the path of $D$ during WWII because we do not using data from the warperiod for our empirical analysis. This is the approximation that underlies (25) in the main text.

\section{Microfoundation for capital adjustment costs:}

The capital goods of technology $\tau$ are all produced by perfectly competitive producers. The individual producers of the vintages then buy the technology-specific capital goods and modify them to the vintagespecific specification. 
The Lagrangian associated with the dynamic profit maximization problem of the supplier of capital goods for technology $\tau$ at time $t$ equals

$$
\mathcal{L}_{\tau}=\int_{t}^{\infty} e^{-\int_{t}^{s} \widetilde{r}_{s^{\prime}} d s^{\prime}} H_{\tau} d s
$$

where $H_{\tau}$ is the current value Hamiltonian. We will drop the time subscript $s$ in what follows. Here

$$
\begin{aligned}
H_{\tau}= & \left(\tilde{R}_{\tau} K_{\tau}-I_{\tau}\right)+ \\
& \lambda_{\tau}\left(I_{\tau}\left(1-\xi\left(I_{\tau} / K_{\tau}\right)\right)-\delta K_{\tau}\right) .
\end{aligned}
$$

Here $\lambda_{\tau}$ is the co-state variable associated with the demand function that the capital goods supplier faces and $\nu_{v}$ is the co-state variable associated with the capital accumulation equation.

The resulting optimality conditions read

$$
\begin{aligned}
& \text { w.r.t. } I_{\tau}: \quad \lambda_{\tau}\left(1-\frac{I_{\tau}}{K_{\tau}} \xi^{\prime}\left(I_{\tau} / K_{\tau}\right)-\xi\left(I_{\tau} / K_{\tau}\right)\right)=1 \text {. } \\
& \text { w.r.t. } K_{\tau}: \quad \tilde{R}_{\tau}=\left(\tilde{r}+\delta-\left(\frac{I_{\tau}}{K_{\tau}}\right)^{2} \xi^{\prime}\left(I_{\tau} / K_{\tau}\right)\right) \lambda_{\tau}-\dot{\lambda}_{\tau} \text {. }
\end{aligned}
$$

The first optimality condition yields that

$$
\lambda_{\tau}=\frac{1}{1-\frac{I_{\tau}}{K_{\tau}} \xi^{\prime}\left(I_{\tau} / K_{\tau}\right)-\xi\left(I_{\tau} / K_{\tau}\right)} .
$$

Taking time derivatives:

$$
\dot{\lambda}_{\tau}=\left(\frac{\dot{I}_{\tau}}{I_{\tau}}-\frac{\dot{K}_{\tau}}{K_{\tau}}\right) \frac{I_{\tau}}{K_{\tau}} \frac{\xi^{\prime \prime}\left(I_{\tau} / K_{\tau}\right) \frac{I_{\tau}}{K_{\tau}}+2 \xi^{\prime}\left(I_{\tau} / K_{\tau}\right)}{1-\frac{I_{\tau}}{K_{\tau}} \xi^{\prime}\left(I_{\tau} / K_{\tau}\right)-\xi\left(I_{\tau} / K_{\tau}\right)} \lambda_{\tau}
$$

Substituting into the FOC w.r.t $K_{\tau}$, it follows that:

$$
\tilde{R}_{\tau}=U C_{\tau}
$$

where the user cost term is given by

$$
\begin{aligned}
U C_{\tau}= & \left(\tilde{r}+\delta-\left(\frac{I_{\tau}}{K_{\tau}}\right)^{2} \xi^{\prime}\left(I_{\tau} / K_{\tau}\right)-\left(\frac{\dot{I}_{\tau}}{I_{\tau}}-\frac{\dot{K}_{\tau}}{K_{\tau}}\right) \frac{I_{\tau}}{K_{\tau}} \frac{\xi^{\prime \prime}\left(I_{\tau} / K_{\tau}\right) \frac{I_{\tau}}{K_{\tau}}+2 \xi^{\prime}\left(I_{\tau} / K_{\tau}\right)}{1-\frac{I_{\tau}}{K_{\tau}} \xi^{\prime}\left(I_{\tau} / K_{\tau}\right)-\xi\left(I_{\tau} / K_{\tau}\right)}\right) \times \\
& \left(1-\frac{I_{\tau}}{K_{\tau}} \xi^{\prime}\left(I_{\tau} / K_{\tau}\right)-\xi\left(I_{\tau} / K_{\tau}\right)\right)^{-1} \cdot
\end{aligned}
$$


The problem of the monopolistic producers of the $v$ capital good supplier of technology $\tau$ is then to

$$
\max _{R_{\tau v}}\left(R_{\tau v}-\tilde{R}_{\tau}\right) Y Z_{v}^{\frac{1}{\mu-1}}\left(\frac{1-\alpha}{W}\right)^{\frac{1-\alpha}{\mu-1}}\left(\frac{\alpha}{R_{\tau v}}\right)^{\epsilon}
$$

which yields the standard solution

$$
R_{\tau v}=\frac{\epsilon}{\epsilon-1} \tilde{R}_{\tau}=R_{\tau}
$$

Functional form for adjustment costs: For the adjustment costs, we consider the following standard quadratic functional form

$$
\xi\left(I_{\tau} / K_{\tau}\right)=\frac{\xi}{2}\left(\frac{I_{\tau}}{K_{\tau}}-\delta\right)^{2}
$$

This yields that the marginal adjustment cost, in terms of $I / K$ net of depreciation, is given by

$$
\xi^{\prime}\left(I_{\tau} / K_{\tau}\right)=\xi\left(\frac{I_{\tau}}{K_{\tau}}-\delta\right)=2 \frac{\xi\left(I_{\tau} / K_{\tau}\right)}{\frac{I_{\tau}}{K_{\tau}}-\delta}
$$

while the second-order derivative is given by

$$
\xi^{\prime \prime}\left(I_{\tau} / K_{\tau}\right)=\xi
$$

Log-linearization: We log-linearize the expression for the rental cost around the steady state $\overline{I_{\tau} / K_{\tau}}=\delta$. The expression we log-linearize is

$$
\begin{aligned}
r_{\tau}= & \ln \left(\frac{\epsilon}{\epsilon-1}\right)-\ln \left(1-\frac{I_{\tau}}{K_{\tau}} \xi^{\prime}\left(I_{\tau} / K_{\tau}\right)-\xi\left(I_{\tau} / K_{\tau}\right)\right) \\
& +\ln \left(\tilde{r}+\delta-\left(\frac{I_{\tau}}{K_{\tau}}\right)^{2} \xi^{\prime}\left(I_{\tau} / K_{\tau}\right)-\left(\frac{\dot{I}_{\tau}}{I_{\tau}}-\frac{\dot{K}_{\tau}}{K_{\tau}}\right) \frac{I_{\tau}}{K_{\tau}} \frac{\xi^{\prime \prime}\left(I_{\tau} / K_{\tau}\right) \frac{I_{\tau}}{K_{\tau}}+2 \xi^{\prime}\left(I_{\tau} / K_{\tau}\right)}{1-\frac{I_{\tau}}{K_{\tau}} \xi^{\prime}\left(I_{\tau} / K_{\tau}\right)-\xi\left(I_{\tau} / K_{\tau}\right)}\right) .
\end{aligned}
$$

Log-linearization yields that

$$
\begin{aligned}
r_{\tau} \approx & \ln \left(\frac{\epsilon}{\epsilon-1}\right)+\ln (\bar{r}+\delta)-\delta^{2} \xi \\
& +\frac{1}{\bar{r}+\delta}(r-\bar{r})+\delta \xi \frac{I_{\tau}}{K_{\tau}} .
\end{aligned}
$$

Hence, this specification adds the investment to capital ratio to the reduced form equation for the $\log$-linearized rental rate. We will return to the term $(r-\bar{r})$ later.

\section{Log-linearization of the interest rate:}

Part of the issue is that, along the transition path, difference between the interest rate and the steady state 
interest rate is not constant. Hence, we need to figure out a proxy for

$$
(r-\bar{r})
$$

This can be done by using the consumption Euler equation, which, for the CRRA preferences that we use, implies that the growth rate of consumption equals the difference between the interest rate and the intertemporal elasticity of subsitution, $\sigma$. Note that in the main text, we assumed log-preferences such that $\sigma=1$.

This means that

$$
r-\bar{r}=\frac{\dot{C}}{C}+\sigma-\bar{r}
$$

Hence, the off-steady-state interest rate path term means that the growth rate of consumption is another righthand-side variable.

\section{Derivation of reduced form equation, (25):}

Substituting (79), (93), (95), and the between sector elasticity parameter, $\theta$, into (23) and (24) we obtain

$$
\begin{aligned}
y_{\tau} & =y+\frac{\theta}{\theta-1}\left[a_{\tau}-(1-\alpha)(y-l)-\alpha r_{\tau}-\alpha \ln \alpha\right] \\
& =y-\frac{\alpha \theta}{\theta-1} \ln \alpha+\frac{\theta}{\theta-1}\left[a_{\tau}-(1-\alpha)(y-l)\right]-\frac{\alpha \theta}{\theta-1} r_{\tau},
\end{aligned}
$$

and

$$
\begin{aligned}
k_{\tau} & =y+\ln \alpha+\frac{1}{\theta-1}\left[a_{\tau}-(1-\alpha)(y-l)-\alpha r_{\tau}-\alpha \ln \alpha\right]-r_{\tau} \\
& =y+\left[1-\frac{\alpha}{\theta-1}\right] \ln \alpha-\frac{1}{\theta-1}\left[a_{\tau}-(1-\alpha)(y-l)\right]-\left[1+\frac{\alpha}{\theta-1}\right] r_{\tau} .
\end{aligned}
$$

For the equation for the output-based measures, $y_{\tau}$, we get

$$
\begin{aligned}
y_{\tau}= & \beta_{0}+y+\beta_{1}[(\mu-1) \ln (t-D-\underline{v})-(1-\alpha)(y-l)]+ \\
& \beta_{2}\left[(t-D-\underline{v})-\frac{(t-1945)}{(t-D-\underline{v})}\left(D^{*}-D\right)\right]+\beta_{3} \frac{\dot{C}}{C}+\beta_{4} \frac{I_{\tau}}{K_{\tau}} .
\end{aligned}
$$


Here

$$
\begin{aligned}
\beta_{0}= & -\frac{\alpha \theta}{\theta-1} \ln \alpha+\frac{\theta}{\theta-1} z_{\underline{v}} \\
& -\frac{\alpha \theta}{\theta-1}\left[\ln \left(\frac{\epsilon}{\epsilon-1}\right)+\ln (\bar{r}+\delta)-\delta^{2} \xi+\frac{\sigma-\bar{r}}{\bar{r}+\delta}\right], \\
\beta_{1}= & \frac{\theta}{\theta-1}, \\
\beta_{2}= & \frac{\theta}{\theta-1} \frac{\gamma}{2}, \\
\beta_{3}= & -\frac{\alpha \theta}{\theta-1} \frac{1}{\bar{r}+\delta}, \text { and } \\
\beta_{4}= & -\frac{\alpha \theta}{\theta-1} \delta \xi .
\end{aligned}
$$

Using the discrete time approximation that $\Delta c_{t} \approx \frac{\dot{C}}{C}$ yields the reduced form equation, (25), presented in the main text.

Similarly, for the equation for the capital-based measures, $k_{\tau}$, we get

$$
\begin{aligned}
k_{\tau}= & \beta_{0}+y+\beta_{1}[(\mu-1) \ln (t-D-\underline{v})-(1-\alpha)(y-l)]+ \\
& \beta_{2}\left[(t-D-\underline{v})-\frac{(t-1945)}{(t-D-\underline{v})}\left(D^{*}-D\right)\right]+\beta_{3} \frac{\dot{C}}{C}+\beta_{4} \frac{I_{\tau}}{K_{\tau}} .
\end{aligned}
$$

In this case

$$
\begin{aligned}
\beta_{0}= & {\left[1-\frac{\alpha}{\theta-1}\right] \ln \alpha+\frac{1}{\theta-1} z_{\underline{v}} } \\
& -\left[1+\frac{\alpha}{\theta-1}\right]\left[\ln \left(\frac{\epsilon}{\epsilon-1}\right)+\ln (\bar{r}+\delta)-\delta^{2} \xi+\frac{\sigma-\bar{r}}{\bar{r}+\delta}\right] \\
\beta_{1}= & \frac{1}{\theta-1} \\
\beta_{2}= & \frac{1}{\theta-1} \frac{\gamma}{2}, \\
\beta_{3}= & -\left[1+\frac{\alpha}{\theta-1}\right] \frac{1}{\bar{r}+\delta}, \text { and } \\
\beta_{4}= & -\left[1+\frac{\alpha}{\theta-1}\right] \delta \xi .
\end{aligned}
$$

